\title{
Quality of Service and its Impact in Achieving Competitive Advantage
}

\author{
Adnan Shamkhi Jabir ${ }^{\mathrm{a}} \quad$ Kamil Shkaier Al.watifi $^{\mathrm{b}}$ Abbas kh. Aljanabi \\ ${ }^{a, b, c}$ College of Administration \& Economics, University of Babylon \\ kamilshkair@gmail.com adnan-sh62@yahoo.com abbas.khudir84@gmail.com
}

Submission date:- 11/7/2018 Acceptance date:- 5/9/2018 Publication date:- 21/1/2019

Keywords: Quality service, Competitive advantage, Simulation.

\begin{abstract}
This study aims to determine the impact of the (QoS) variable on the competitive advantage variable. To achieve this, the study relied on quality of service in terms of reliability, responsiveness, flexibility, safety and contentivity and its competitive advantage in terms of cost, quality, flexibility and delivery. The study tried to answer the questions of the problem, the most important of which is the quality of service in the organization in question? What is the level of competitive advantage offered by the organization in question? Is there a relationship between quality of service and competitive advantage in the organization in question? The study was conducted in the General Company for the distribution of petroleum products / Central Euphrates Distribution Authority / Babel Branch. The questionnaire was used to obtain the necessary data, as well as personal interviews. The opinions of 150 workers were analyzed in addition to 35 customers. The simple correlation coefficient was used to measure the correlation between the variables and the (T) test to determine the significance of the simple and multiple regression equation and also to use the analysis of the (Anova). The simulation method was used to generate data (views) of all the resolution sections that were pre-designed according to the five-dimensional Likert scale for the sample size $(n=150)$. The study sought to achieve a set of objectives, the most important of which is to identify the relationship between quality of service, competitive advantage and the impact of quality of service on the competitive advantage, to make some recommendations that can contribute to improving the status of the organization in question. The study concluded with a number of conclusions, the most important of which is the organization's interest in responding quickly to the customer's needs when requesting service, noting the importance of the organization to provide most of the needs of the citizens of fuel on demand despite the difficult conditions of the country. The most important recommendations included the organization's interest in quickly responding to customers' requests, so it is important for them to maintain and develop these gains.
\end{abstract}




\section{جودة الخدمة واثرها في تحقيق الميزة التنافسية}

\section{دراسة تحليلية لآراء عينة من الزبائن والعاملين في شركة توزيع المنتجات النفطية/ هيأة توزيع الفرات

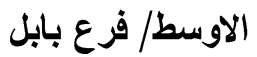 \\ عباس خضر عباس \\ عدنان شمخي جابر \\ (كلية الادارة والاقتصاد، جامعة بابل \\ كامل شكير الوطيفي}

kamilshkair@gmail.com adnan-sh62@yahoo.com abbas.khudir84@gmail.com

تهدف هذه الدراسة الى تحديد تأثير (متغير جودة الخدمة) في متغير الميزة التتافسية، ولتحقيق ذلك اعتمدت الدراسة على كل من جودة الخدمة

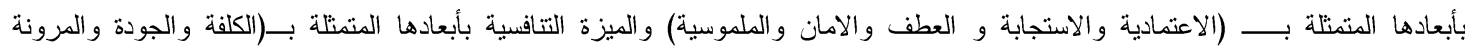

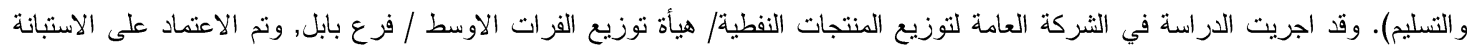

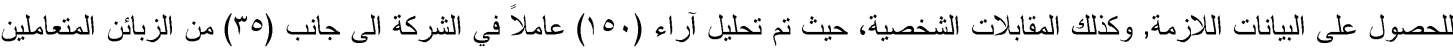

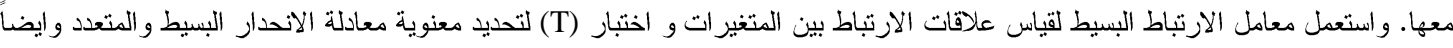

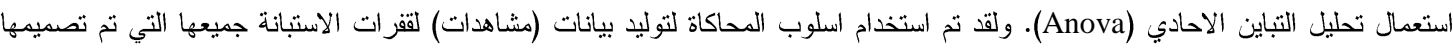

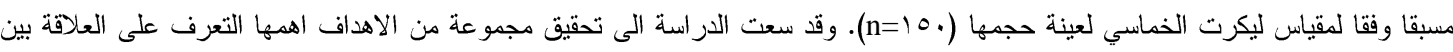

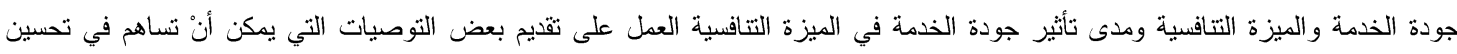

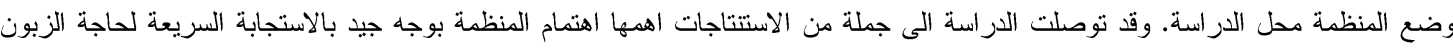

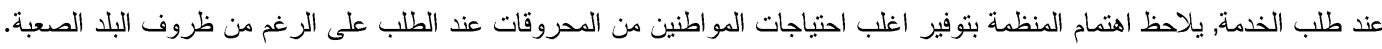
الكلمات الالة: جودة الخدمة, الميزة التتافسية, المحاكاة.

المقدمة:

تواجه منظمات الأعمال تحديات في غاية الحدة والحداثة فرضتها التغيرات الييئية المعاصرة منها (الاهتمام برأس المال الفكري، وبناء فرق

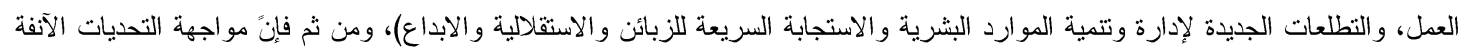

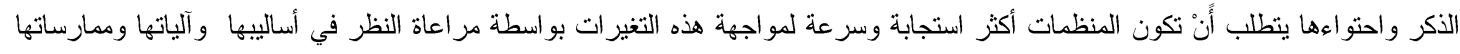

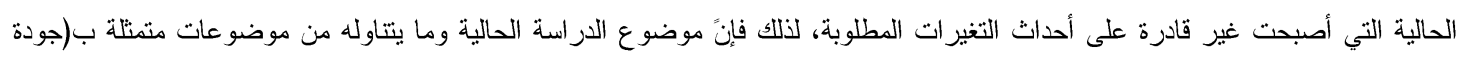

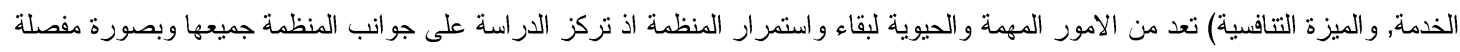

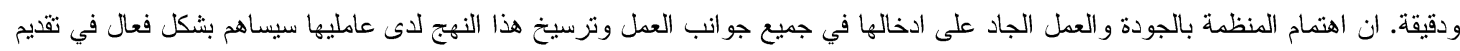
المنظمة خدمة ذات جودة عالية مما يعزز من مكانتها ويزيد من قدرتها على خلق ميزة تتافسية قد تعجز بقية المنظمات عن بلو غها, وبالتالي القدرة على البقاء و الاستمر ار.

1- منهجية الار اسة

1.1

تواجه المنظمات الحالية العديد من الضغوط و التحديات الداخلية والخارجية، التي يمكن ان تؤثز على بقائها وقـدرتها علــى الاســتمرار

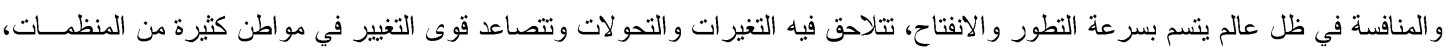

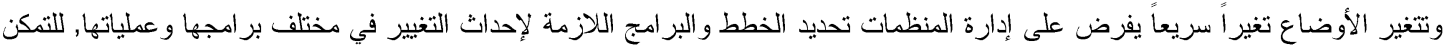

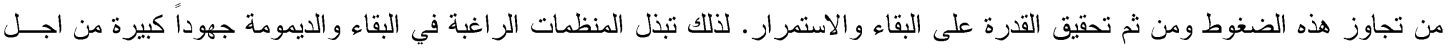

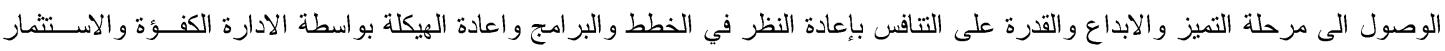

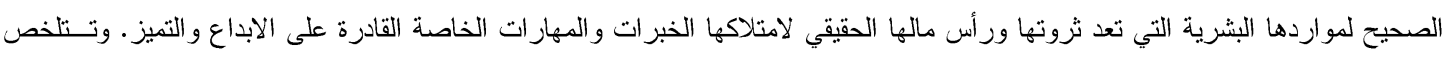

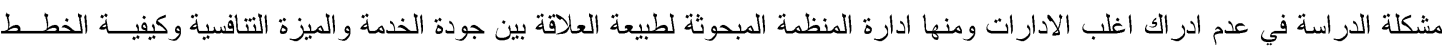

و البرامج الكفيلة في تحقيق المو ائمة بين هذين المتغيرين. و استتاداً الى ما نقدم ذكره تتجسد مشكلة الدراسة في الاجابة عن التساؤلات الاتية: 


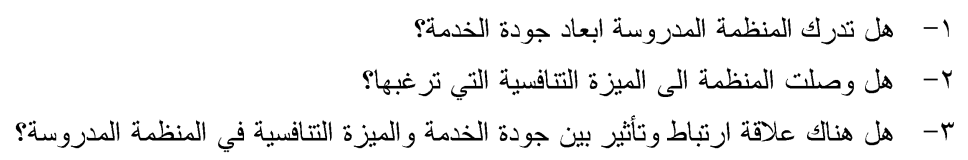

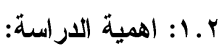
ا - تأني اهمية الدراسة من اهمية المتغيرات المدروسة اولاً وهي: (جودة الخدمة والميزة النتافسية) ومن اهمية المنظمة المدروسة (شركة توزيع

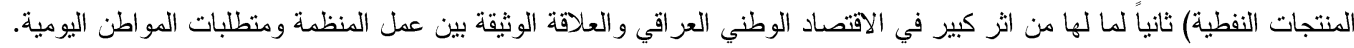

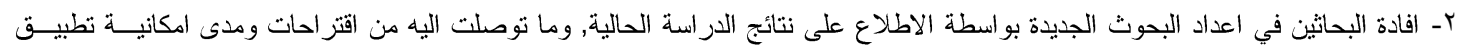

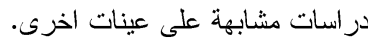

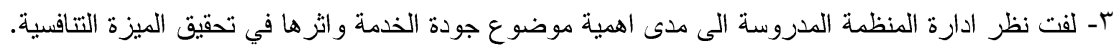

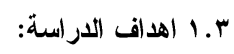
1- التعرف على العلاقة بين جودة الخدمة والميزة التتافسية.

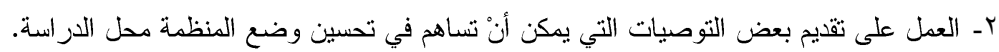

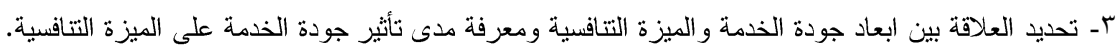
ع ـ أفطط الار اسة الفرضي:

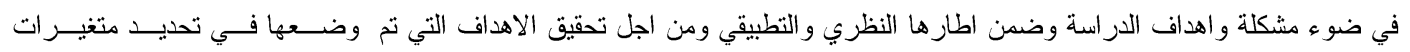

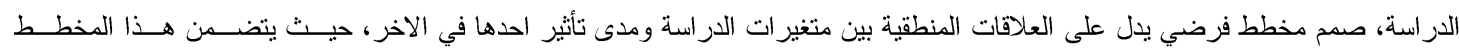
متغيرين هما: 1- المتغير المستقل: ويتمثل بجودة الخدمة بأبعادها الاتية (الاعتمادية والاستجابة والعطف و الملموسية والامان).

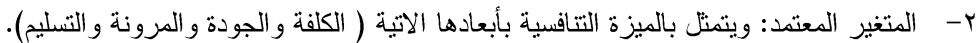

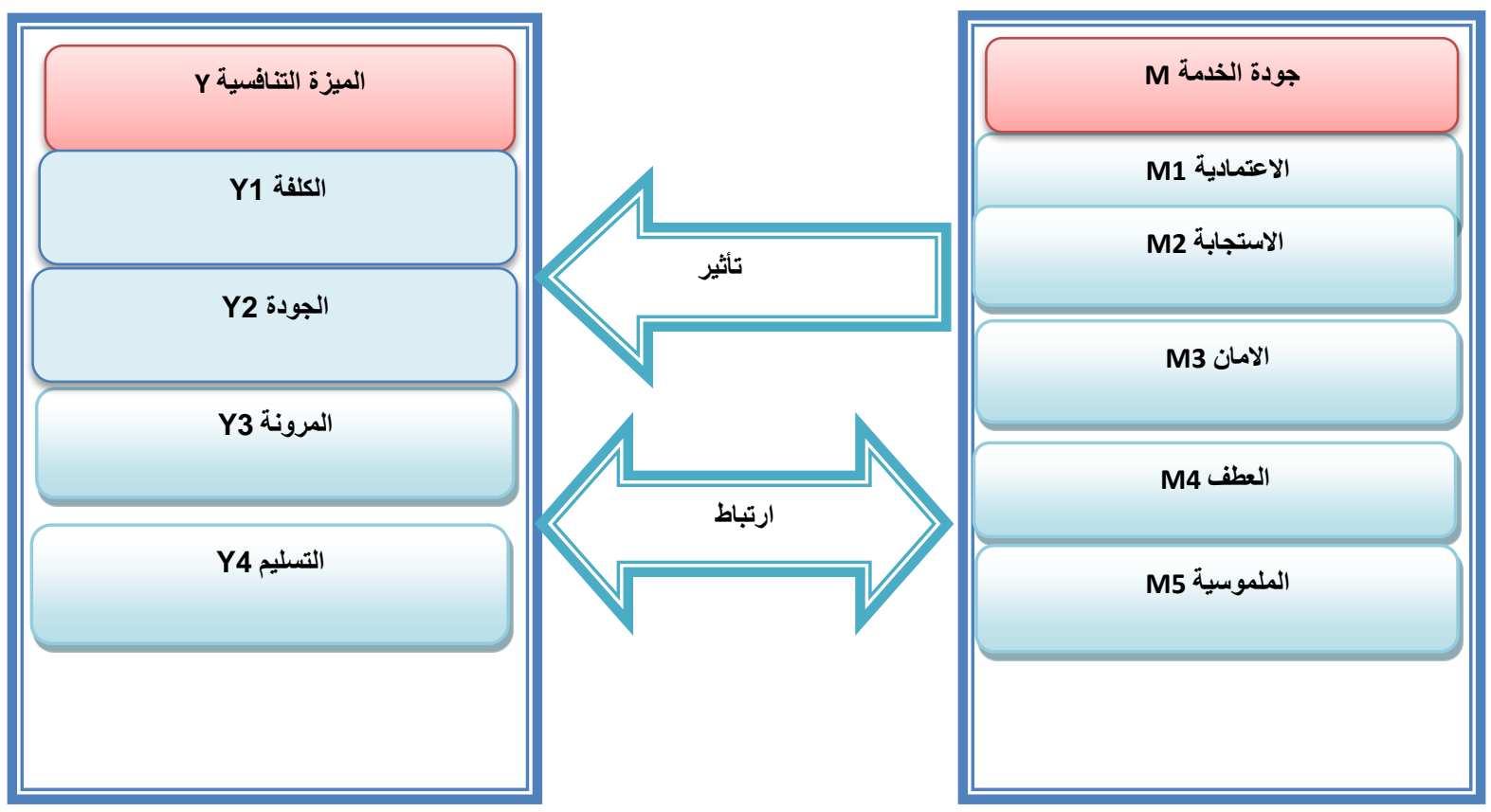

شكل (1) مخطط الار اسة الفرضي 


$$
\text { هـ ا : فرضيات الاراسة: تم صياغة فرضيات الدراسة وكالاتي: }
$$

القرضية الرئيسة الاولى: توجد علاقة ارتباط ذات دلالة معنوية بين جودة الخدمة و الميزة التنافسية بمؤشر اتها. الفرضية الرئيسة الثانية: نوجد علاقة تأثير ذات دلالة معنوية لجودة الخدمة في تحقيق الميزة التتافسية بمؤشر اتها.

1- حدود الدراسة المكانية: تم اختيار الثركة العامة لتوزيع المنتجات النفطية/ هيأة توزيع الفرات الاوسط/ فرع بابل كموقـع لدـدود الدراســة المكانية.

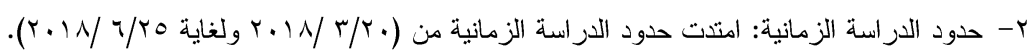
r- حدود الدراسة البشرية: تم تطبيق الدراسة على عينة من العاملين في شركة توزيع المنتجات النفطية/ هيأة توزيع الفرات الاوسط/ فرع بابل

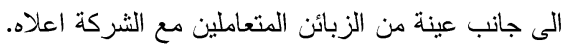

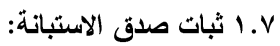
تحقق الباحثين من مدى صدق الاتساق الداخلي ومدى ثبات الاستبانة باستعمال معامل (الفا كرونباخ) وعلى النحو الاتي:

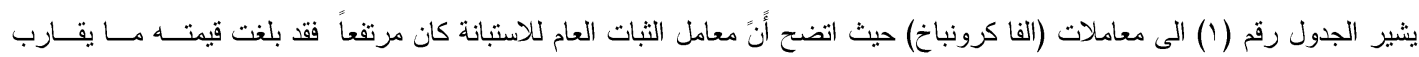

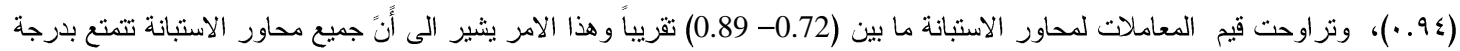
عالية ومقبولة من الثبات ومما يؤدي الى امكانية الاعتماد عليها في إجراء التطبيق و التحليل الميداني.

الجدول رقم (1) معاملات الفا كرونباخ لقياس ثبات محاور الاستبانة

\begin{tabular}{|c|c|c|}
\hline قيمة معامل الثبات & عدد العبارات & المحور \\
\hline 0.76 & 5 & الاعتمادية \\
\hline 0.79 & 5 & الاستجابة \\
\hline 0.79 & 5 & العطف \\
\hline 0.72 & 5 & الامان \\
\hline 0.82 & 5 & الملموسية \\
\hline 0.92 & 25 & المحاور جميعاً \\
\hline 0.89 & 5 & الكلفة \\
\hline 0.85 & 5 & الجودة \\
\hline 0.75 & 3 & المرونة \\
\hline 0.83 & 5 & التسليم \\
\hline 0.94 & 18 & المحاور جميعا \\
\hline
\end{tabular}

المصدر : الباحثين اعتمادا على نتائج الحاسوب باستخلام برنامج (spss v.17) 


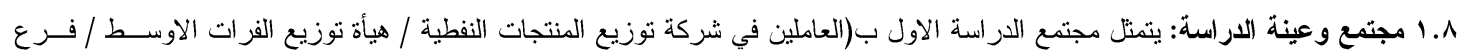

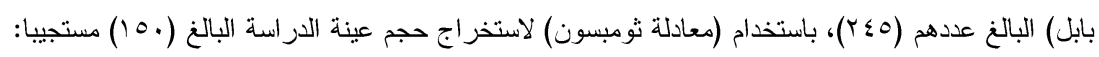

$$
n=\frac{N \times p(1-p)}{\left.\left.\llbracket N-1 \times\left(d^{2} \div z^{2}\right)\right]+p(1-p)\right]}
$$

$$
\begin{gathered}
N=\frac{245 * 0.50(1-0.50)}{\left((245-1) *(0.05)^{2} /(0.96)^{2}+0.50(1-0.50)\right)} \\
N=\frac{61.25}{0.408788005} \\
N=149.833164 \quad=150
\end{gathered}
$$

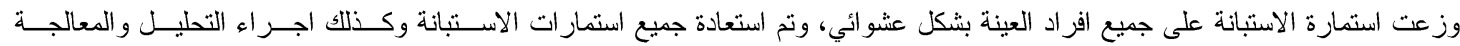

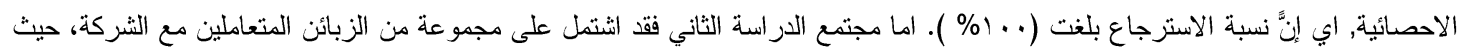

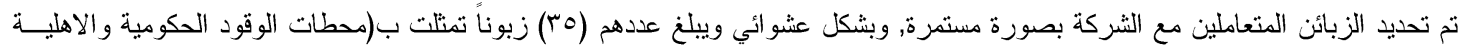

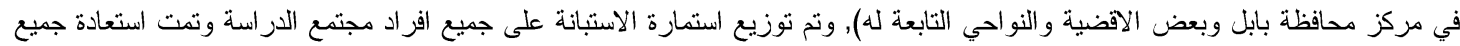

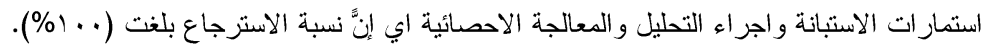

\section{r- ب المرتكزات النظرية و الفكرية}

1.Y مفهوم جودة الخدمة concept of Quality service

جودة الخدمة (QS)، في تصور ها المعاصر، هي المقارنة بـين التوقعـات(E) (E) (E) مـن الخدمــة و الأداء

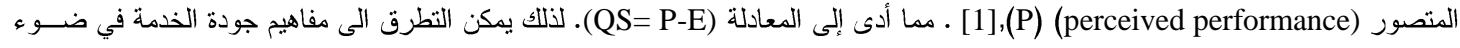
المنظور اعلاه:

جودة الخدمة هي أن يلبي اداء الخدمة توقعات الزبون, ويتفوق عليها, اذ لا يكفي أن تكون الخدمة مقبولة مقارنة بسعرها، أو أن تتم الخدمة بلا

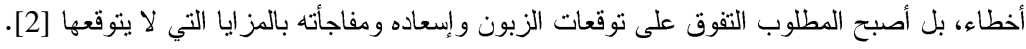
"وتعرف جودة الخدمة بأنها مقياس لمدى نجاح مستوى الخدمة المقدمة مع توقعات الزبائن [3]. ويعرفها [4] "بالدرجة التي يمكن ابتداء منها إرضاء الزبون بتلبية حاجاته ورغباته وتوقعاته باستمر ار". ويعرف [5] جودة الخدمة على انها

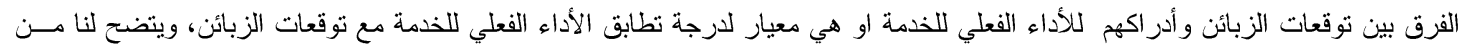
التعريف إنه يركز على الجودة من منظور الزبون.

\section{Importance of Service Quality الهمية جودة الخدمة}

تتمثل الهية جودة الخدمة بالاتي:

ا - نُمو مجال الخدمة: ازداد عدد الدنظمات التي تقوم بتقديم الخدمات، فمثلا اكثر من نصف المنظمات الأمريكية يتعلق نشاطها بنقديم الخدمات,

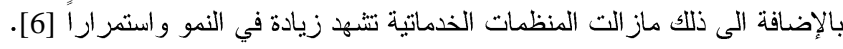
ץ- ازدياد المنافسة: إنّ زيادة عدد المنظمات سوف يخلق منافسة شديدة بينها لذلك فإنّ الاعتماد على جودة الخدمة سوف يمنح هـذهـ المنظمـات مز ايا تتافسية عديدة [7].

ץ- سمعة المنظمة: للجودة اهمية كبيرة في تعظيم سمعة المنظمة، فعندما تر اعي المنظمة معايير الجودة في خدماتها فسيكون ذلك بمنزلة الترويج لخدماتها من خلال الصورة الايجابية المدركة التي ستتولد في اذهان زبائنها، و التي تعد بمثابة الاعلان عن خدمات التهات المنظمة [8]. 
ع - مسؤولية الخدمات: تعد المنظمة المسؤول الوحيد عن الذذمات التي تقدمها, لذلك يجب عليها وضع شروط على عمليات تقديم الخذمـة مـن

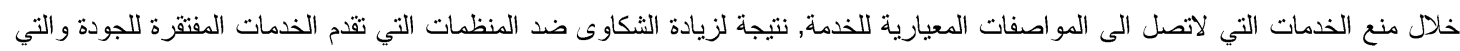

ه- كلف اوطأ وحصة سوق عالية: الجودة تعني عمل الثيء بصورة صحيحة من المرة الاولى لجميع عمليات ومراحل تقديم الخدمة, الامر الذي

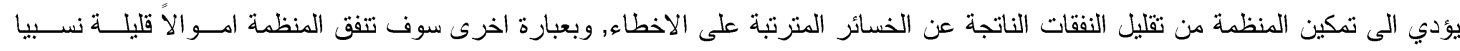

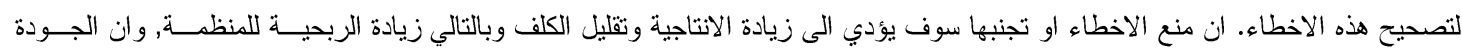

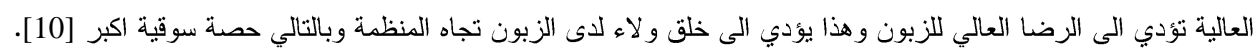

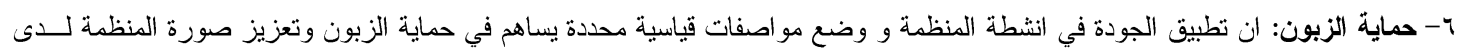

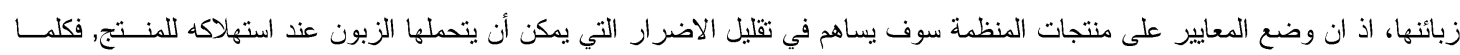

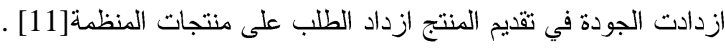

The dimensions of Quality of Service : بعاد جودة الخدمة

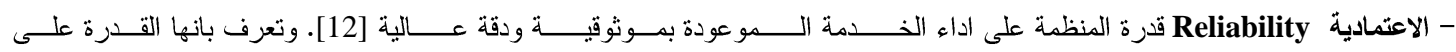

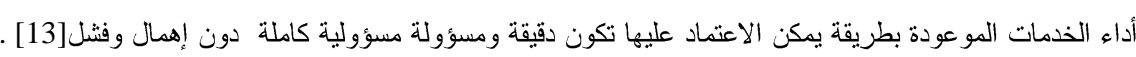

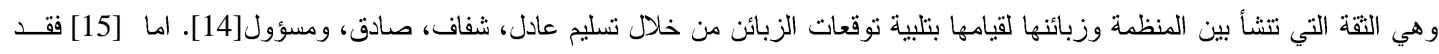

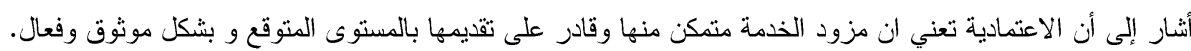

Responsiveness الاستجابة الاستجابة تتعلق بمدى سرعة ودقة المنظمة للرد على طلب الزبون للحصول على المعلومات. فالمنظمات يجب أن تكون علـى اســتعداد

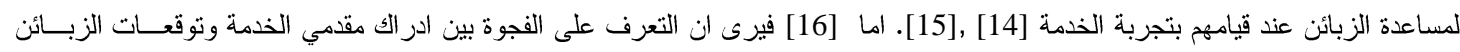

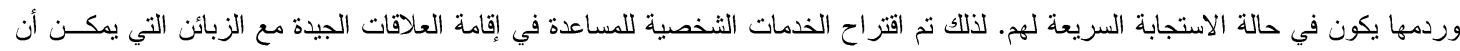
تؤدي إلى الثقة و الو لاء.

\section{Empathy ب العطف}

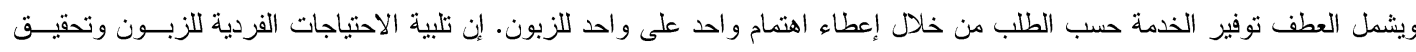

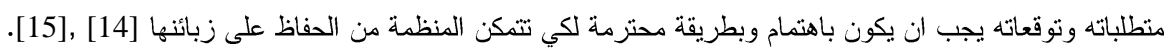

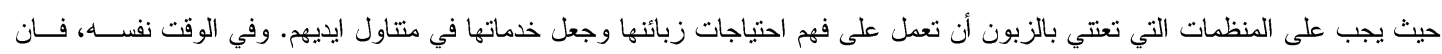

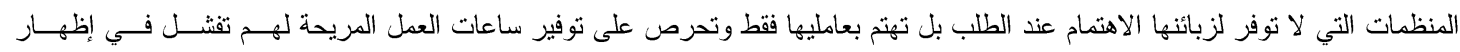
سلوكيات التعاطف [5].

Assurance ؛ ويثير بعد الامان الى مهارة و قدرة العاملين على زرع الطمانينة في نفوس الزبائن و الخبرة في الرد على أسئلتهم [17]. ويعرف ايضا

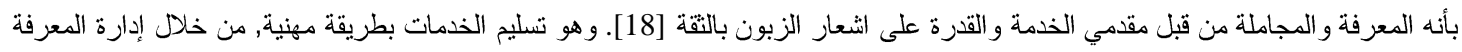

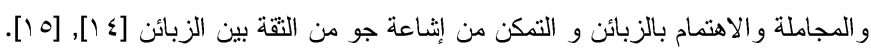

Tangibility الملموسية تتير الملموسية الى مظهر التسهيلات المادية من اجهزة والمعدات والافراد ومواد الاتصالات [19]. و واضاف [20] ان بعد الملموسية يمكـن

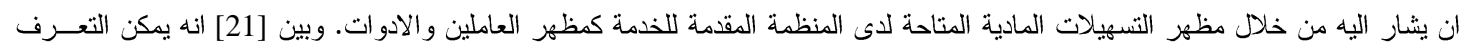
على الملموسية من خلال جودة الاثاث الموجود وهندسة موقع العمل من خلال توفير المكان المناسب للعاملين لكي يتمكنوا من تقديم الخدمة الجيدة

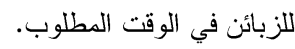




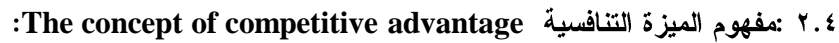

برز مفهوم الميزة التنافسية في حقل الإدارة الاستراتيجية في فترة الستينات من القرن العشرين في كتابات عدد من الففكرين الإداريـين

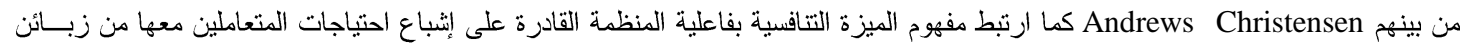

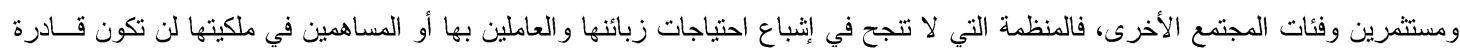

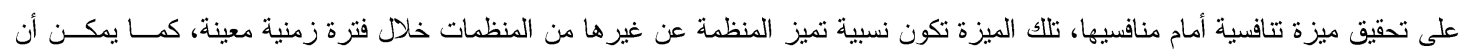

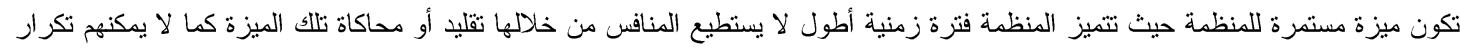

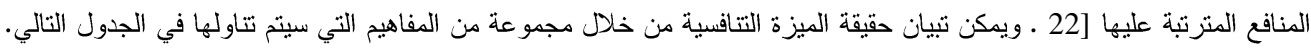

جدول رقم (r) حقيقة الميزة التنافسية من خلال مجموعة من المفاهيم

\begin{tabular}{|c|c|c|}
\hline مفهوم الميزة التنافسية & الباحثين & $ت$ \\
\hline "المنفعة المحققة في حالة ما إذا تمكنت المنظمة من عرض منتج تنافسي يسمح لها بتعظيم ربحيتها". & $($ VanZyl : $2006: 19)$ & 1 \\
\hline 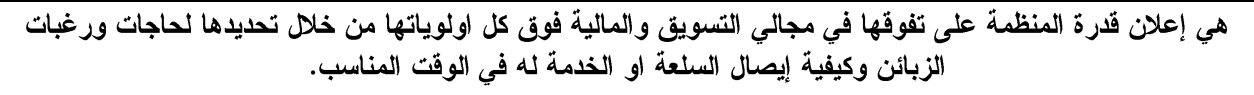 & $\begin{array}{l}\text { Evans\& Collier:2007 } \\
: 118\end{array}$ & 2 \\
\hline أنها سعى المنظمة لإشاء أو امتلاك ميزة فريدة تميزها عن غيرها من المنظمات العاملة فى الصناعة نفسها لكى تحقى & Gould $2008: 4$ & 3 \\
\hline 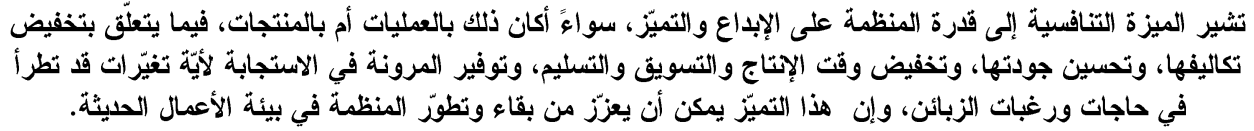 & $\begin{array}{l}\text { (Berdine,et.al., } \\
\text { 2008: 5) }\end{array}$ & 4 \\
\hline
\end{tabular}

المصدر: الباحثين اعتمادا على المصادر الموجودة في الجدول

: The importance of competitive advantage أهية الميزة التنافسية: r.०

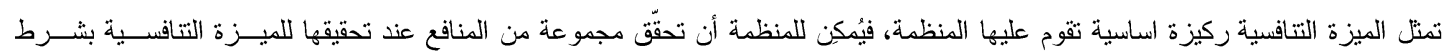

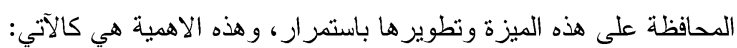

1- إن التفوق على المنافسين يساعد في تحقيق رضا وو لاء الزبائن للمنظمة، إذ يتم التزكيز على الإبداع واستعمال التكنولوجيــا الحديثــة لتقـــيم

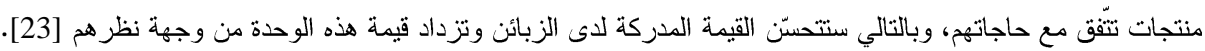

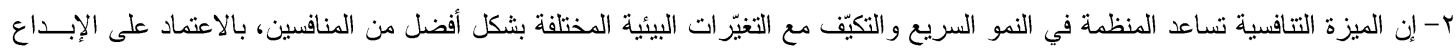
و إتّباع أفضل الطرق للتصميم والإنتاج والتسويق، وبالتالي التوسّع في الأسواق واستغلال المزيد من فرص العمل [24]. ب- إن تميّز المنظمة بمنتجاتها عن المنافسين، تجعل الزبائن مستعدين لافع أسعارًا أعلى للحصول على المنتجات المتميّزة التي تقـــمها المنظمـــة إليهم، وبذلك يمكن لهذه الوحدة وضع سياسة سعرية للنتجاتها وبالتالي ستزداد الربحية[25].

ع - تساعد الميزة التتافسية في زيادة الحصّة السوقية للمنظمة من خلال التحسينات الملحوظة في منتجاتها وخدماتها المقدّة إلى الزبائن وبالتـالي

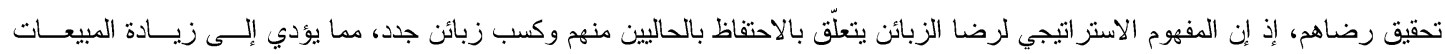

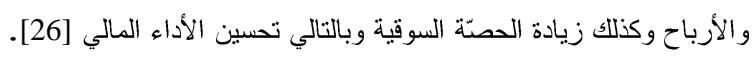

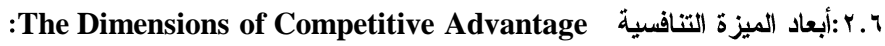

- الكلفة Cost: تسعى المنظمات الى ايصال السلع والخدمات بأقل سعر ممكن للزبائن الداخليين و الخارجيين بافتز اض أنه كلما استطاعت المنظمة

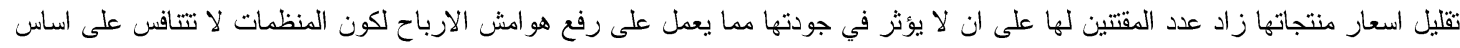

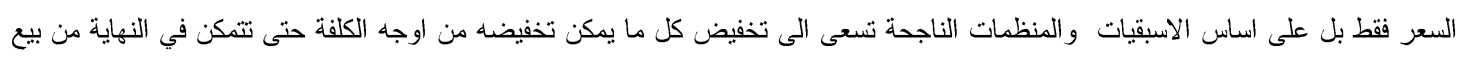

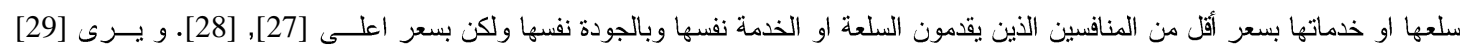
30], 
أ- الاستثمار الأقل في الموارد ( كلف التكنلوجيا والتسهيلات والأدوات والأموال والصيانة).

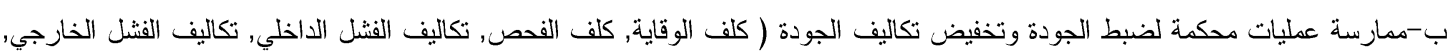
و إعادة العمل و التالف).

ت-الاستعمال الاقتصادي للموجودات الثابتة و المتاولة. ث-كلف المو اد والأمو ال المصروفة على المواد المستهلكة ومجال استههاكها. ج- المحافظة على أدنى المستويات من الخزين وبما يؤمن عدم توقف عمليات الإنتاج.

ץ- الجودة Quality: تعد الجودة عامل النجاح الحاسم لكثير من المنظمات والمرتكز الاساس لها لتحقيق الميزة التتافسية، ويسـى الزبــون

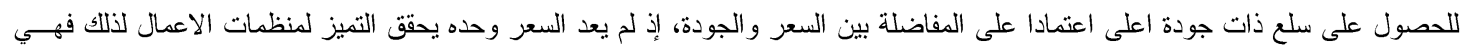
تسعى اليوم الى تحقيق جودة اعلى في سلعها وخدماتها [28].

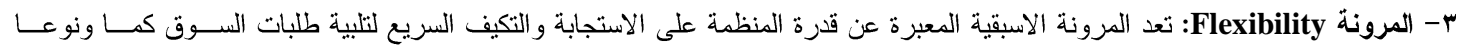

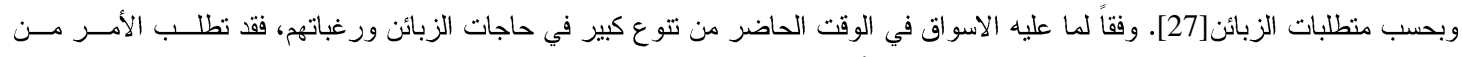

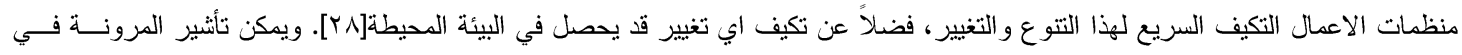

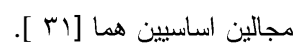

أ- قدرة المنظمة في مسايرة التطور ات الحاصلة في مجال التكنولوجيا وتصميم المنتجات على وفق تفضيلات الزبائن، لكون المستهلك وسـلـوكه

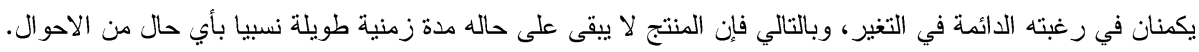

ب- قدرة المنظمة على الاستجابة للتغير في حجم الانتاج بالزيادة او النقصان وبحسب مستويات الطلب، وبالتالي يجب ان يكون لــى المنظمــة الاستعداد الكافي و القدرة على العمل في بيئة غير مستقرة ومتقلبة.

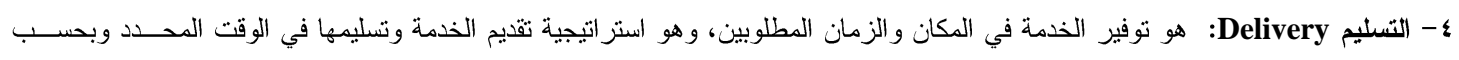

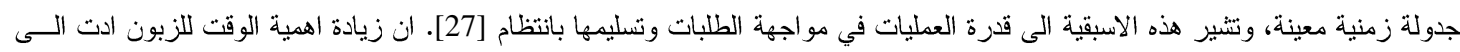

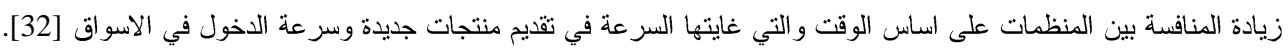

ب- مناقشة وتحليل البيانات و المعلومات

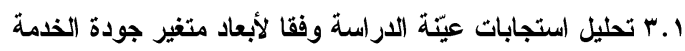

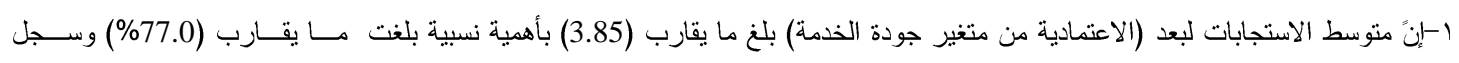
الانحر اف المعياري قيمة (0.81) وقد كانت أعلى أهمية نسيبة للفقرة (Q5) (توافير الأفر انظمة التوثيق و السجلات الاقيقة) حيث بلغت أهميتها النسبية

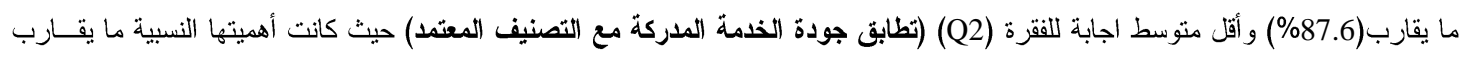

ب-تثير نتائج الجدول رقم (ب) الى أن الأهمية النسبية لبعد (الاستجابة من متغير جودة الخدمة) بلغت ما يقارب (77.6\%) و الوســط الحسـابي

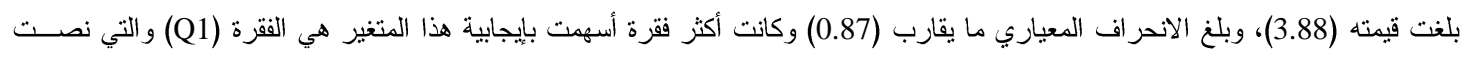

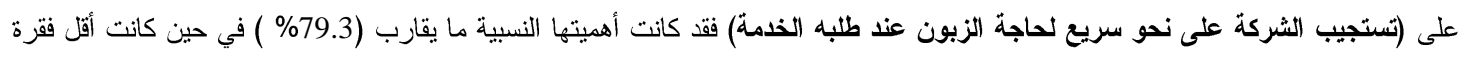

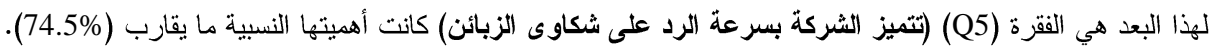

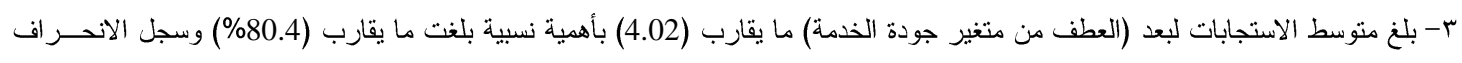

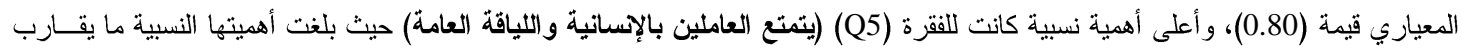

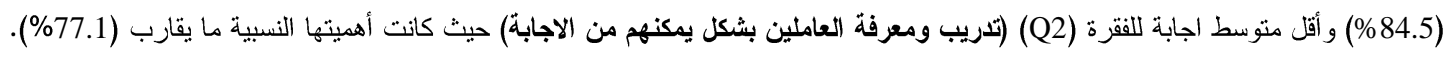

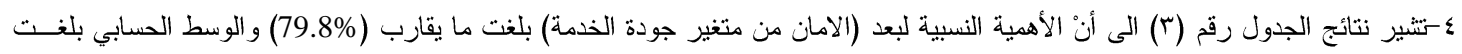

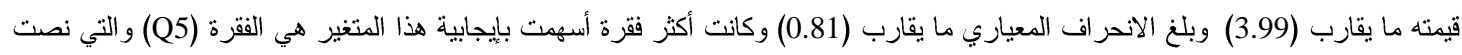

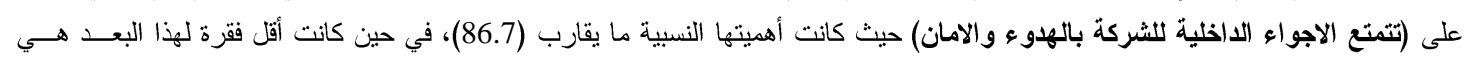

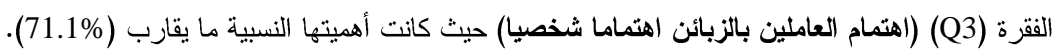

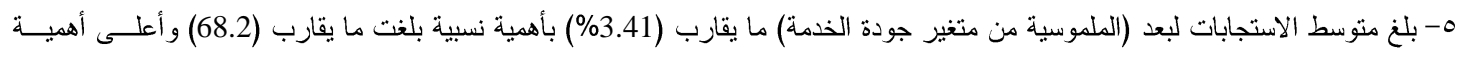

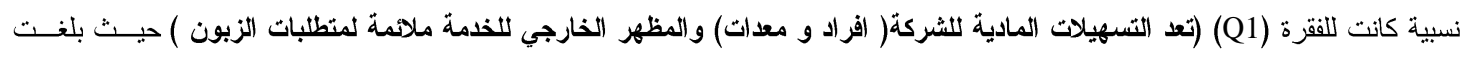

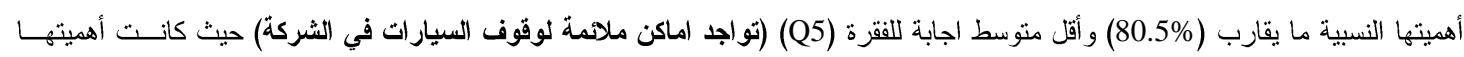

النسبية ما يقارب (55.3\%). 


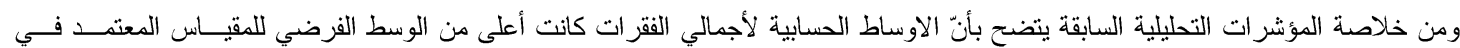

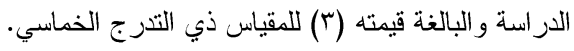

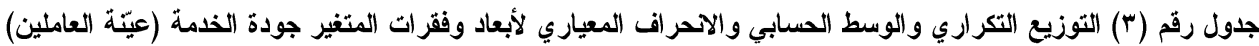

\begin{tabular}{|c|c|c|c|c|c|}
\hline \multicolumn{6}{|c|}{ Descriptive Statistics } \\
\hline Importance & Std. Deviation & Mean & Sum & $\mathbf{N}$ & الفقرة \\
\hline 79.6 & 0.68 & 3.98 & 597 & 150 & Q1 \\
\hline 70.4 & 0.90 & 3.52 & 528 & 150 & Q2 \\
\hline 70.9 & $\mathbf{0 . 8 8}$ & 3.55 & 532 & 150 & Q3 \\
\hline 76.7 & $\mathbf{0 . 8 3}$ & $\mathbf{3 . 8 3}$ & 575 & 150 & Q4 \\
\hline 87.6 & 0.78 & 4.38 & 657 & 150 & Q5 \\
\hline 77.0 & 0.81 & 3.85 & & & الاعتمادية \\
\hline 79.3 & 0.87 & 3.97 & 595 & 150 & Q1 \\
\hline 77.9 & 0.84 & 3.89 & 584 & 150 & Q2 \\
\hline 77.9 & 0.84 & 3.89 & 584 & 150 & Q3 \\
\hline 78.3 & 0.80 & 3.91 & 587 & 150 & Q4 \\
\hline 74.5 & 0.97 & 3.73 & 559 & 150 & Q5 \\
\hline 77.6 & 0.87 & 3.88 & & & الاستجابة \\
\hline 82.8 & 0.70 & 4.14 & 621 & 150 & Q1 \\
\hline 77.1 & 0.88 & 3.85 & 578 & 150 & Q2 \\
\hline 77.6 & $\mathbf{0 . 8 3}$ & 3.88 & 578 & 149 & Q3 \\
\hline 80.4 & 0.84 & 4.02 & 603 & 150 & Q4 \\
\hline 84.5 & 0.78 & 4.23 & 634 & 150 & Q5 \\
\hline 80.4 & 0.80 & 4.02 & & & العطف \\
\hline 84.7 & 0.68 & 4.23 & 635 & 150 & Q1 \\
\hline 81.9 & 0.74 & 4.09 & 614 & 150 & Q2 \\
\hline 71.1 & 0.99 & 3.55 & 533 & 150 & Q3 \\
\hline 75.1 & 0.84 & 3.75 & 563 & 150 & Q4 \\
\hline 86.7 & 0.79 & 4.33 & 650 & 150 & Q5 \\
\hline 79.8 & 0.81 & 3.99 & & & الامان \\
\hline 80.5 & 0.67 & 4.03 & 604 & 150 & Q1 \\
\hline 72.5 & 0.97 & 3.63 & 544 & 150 & Q2 \\
\hline 69.9 & 0.96 & 3.49 & 524 & 150 & Q3 \\
\hline 62.9 & 1.11 & 3.15 & 472 & 150 & Q4 \\
\hline 55.3 & 1.51 & 2.77 & 415 & 150 & Q5 \\
\hline 68.2 & 1.04 & 3.41 & & & الملموسية \\
\hline 68.42 & 0.87 & 3.83 & & & كافة ابعاد المتغير \\
\hline
\end{tabular}

SPSS V.17 المصدر : من إعداد الباحثين بالاعتماد على نتائج الحاسبة باستخدام برنامج

r.r تصليل استجابات عينّة الاراسة وفقاً لأبعاد متغير الميزة التنافسية

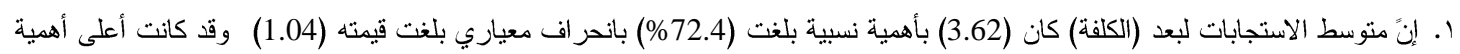

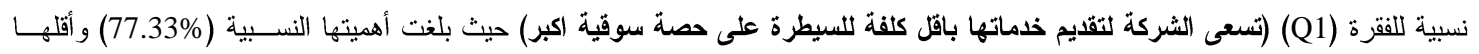


للفقرة (Q5) (تستثر ادارة الشركة الوقت بالثكل الامثل لتخفيض كلف الاجور والتشغيل). حيث سّجل منوسط الاستجابة لها (3.45) بأهمية نسبية

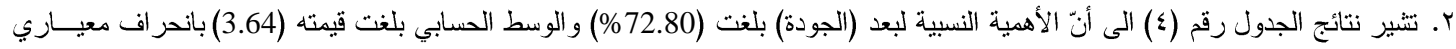

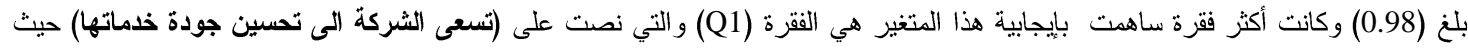

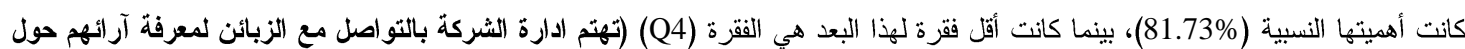

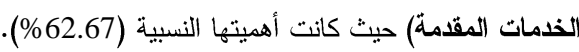

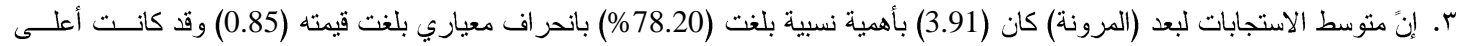

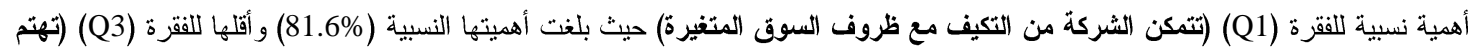

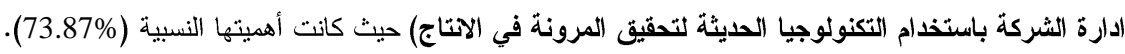

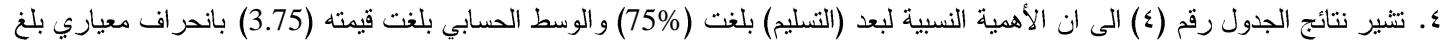

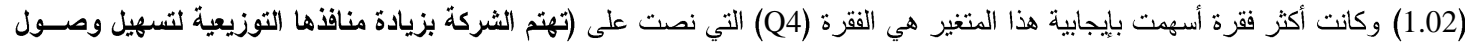

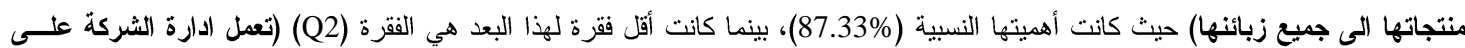

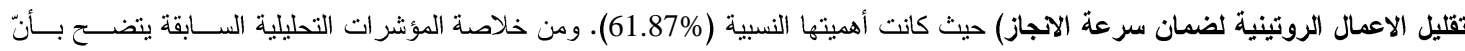

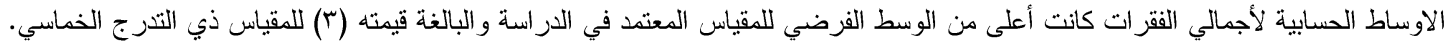

جدول رقم(؛) التوزيع التكر اري و الوسط الحسابي والاحر اف المعياري لأبعاد متغير الميزة التنافسية (عيّة العاملين)

\begin{tabular}{|c|c|c|c|c|c|}
\hline \multicolumn{6}{|c|}{ Descriptive Statistics } \\
\hline importance & Std.Deviation & Mean & Sum & $\mathbf{N}$ & الفقرة \\
\hline $\mathbf{7 7 . 3 3}$ & 0.95 & 3.87 & 580 & 150 & Q1 \\
\hline 71.87 & 1.03 & 3.59 & 539 & 150 & Q2 \\
\hline 70.93 & 1.10 & 3.55 & 532 & 150 & Q3 \\
\hline 72.67 & 1.09 & 3.63 & 545 & 150 & Q4 \\
\hline 68.93 & 1.06 & 3.45 & 517 & 150 & Q5 \\
\hline 72.40 & 1.04 & 3.62 & & & الكلفة \\
\hline 81.73 & 0.86 & 4.09 & 613 & 150 & Q1 \\
\hline 75.60 & 0.92 & 3.78 & 567 & 150 & Q2 \\
\hline 76.13 & 0.87 & 3.81 & 571 & 150 & Q3 \\
\hline 62.67 & 1.22 & 3.13 & 470 & 150 & Q4 \\
\hline 68.27 & 1.04 & 3.41 & 512 & 150 & Q5 \\
\hline 72.80 & 0.98 & 3.64 & & & 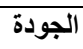 \\
\hline 81.60 & 0.76 & 4.08 & 612 & 150 & Q1 \\
\hline 78.93 & 0.78 & 3.95 & 592 & 150 & Q2 \\
\hline 73.87 & 1.01 & 3.69 & 554 & 150 & Q3 \\
\hline 78.20 & 0.85 & 3.91 & & & المرونة \\
\hline 78.93 & 0.85 & 3.95 & 592 & 150 & Q1 \\
\hline 61.87 & 1.33 & 3.09 & 464 & 150 & Q2 \\
\hline 77.73 & 0.97 & 3.89 & 583 & 150 & Q3 \\
\hline 87.33 & 0.85 & 4.37 & 655 & 150 & Q4 \\
\hline 69.20 & 1.08 & 3.46 & 519 & 150 & Q5 \\
\hline 75.00 & 1.02 & 3.75 & & & التسليم \\
\hline 60.71 & 0.99 & 3.71 & & & كافة فقر \\
\hline
\end{tabular}

SPSS V.17 المصدر : من إعداد الباحثين بالاعتماد على نتائج الحاسبة باستخدام برنامجيع 
r.r:- اختبار الفرضية الرئيسة الاولى وتفرعاتها:-

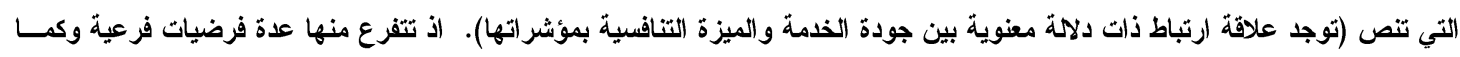
موضح في ادناه:-

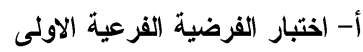
(توجد علاقة ارتباط ذات دلالة معنوية بين الاعتمادية والميزة التتافسية بمؤشراتها) تدل نتائج تحليل الارتباط لبعد جــودة الخدمـــة (الاعتماديــة)

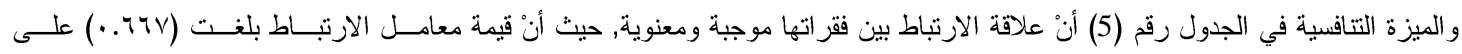

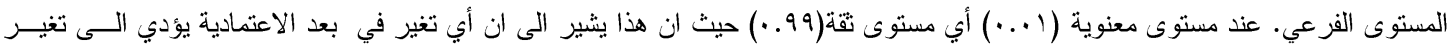

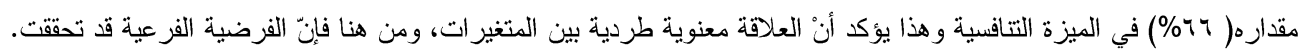

Correlations جدول رقم (5) قيمة معامل الارتباط بين بعد الاعتمادية والميزة التنافسية

\begin{tabular}{|c|c|c|c|}
\hline & & الاعتمادية & الميزة التنافسية \\
\hline الاعتمادية & $\begin{array}{c}\text { Pearson Correlation } \\
\text { Sig. (2-tailed) } \\
\text { N }\end{array}$ & $\begin{array}{c}1 \\
150\end{array}$ & $\begin{array}{l}.667 \\
.000 \\
150\end{array}$ \\
\hline الميزة التنافسية & $\begin{array}{c}\text { Pearson Correlation } \\
\text { Sig. (2-tailed) } \\
\text { N }\end{array}$ & $\begin{array}{l}.667 \\
.000 \\
150\end{array}$ & $\begin{array}{c}1 \\
150\end{array}$ \\
\hline
\end{tabular}

**. Correlation is significant at the 0.01 level (2-tailed).

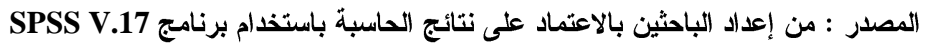

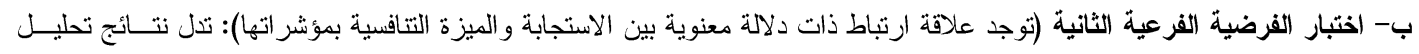

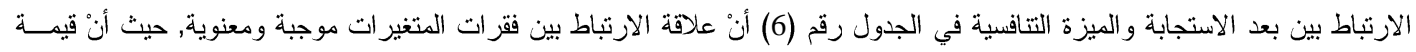

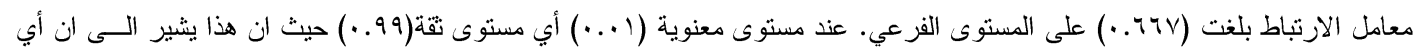

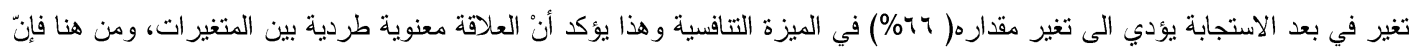

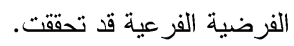

Correlations جدول رقم (6) قيمة معامل الارتباط بين بعد الاستجابة والميزة التنافسية

\begin{tabular}{|c|c|c|c|}
\hline & & الاستجابة & الميزة التنافسية \\
\hline الاستجابة & $\begin{array}{l}\text { Pearson Correlation } \\
\qquad \begin{array}{c}\text { Sig. (2-tailed) } \\
\text { N }\end{array}\end{array}$ & $\begin{array}{c}1 \\
150\end{array}$ & $\begin{array}{l}.667 \\
.000 \\
150\end{array}$ \\
\hline التنافيزية & $\begin{array}{c}\text { Pearson Correlation } \\
\text { Sig. (2-tailed) } \\
\text { N }\end{array}$ & $\begin{array}{l}.667 \\
.000 \\
150\end{array}$ & $\begin{array}{c}1 \\
150\end{array}$ \\
\hline
\end{tabular}

**. Correlation is significant at the 0.01 level (2-tailed).

\section{SPSS V.17 المصدر : من إعداد الباحثين بالاعتماد على نتائج الحاسبة باستخدام برنامج}

ج- اختبار الفرضية الفرعية الثالثة (توجد علاقة ارتباط ذات دلالة معنوية بين العطف و الميزة التتافسية بمؤشر اتها):

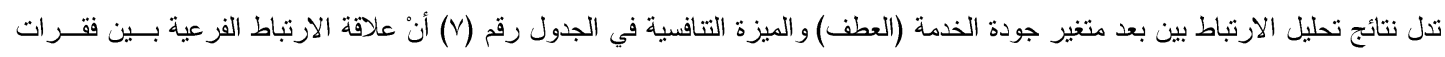

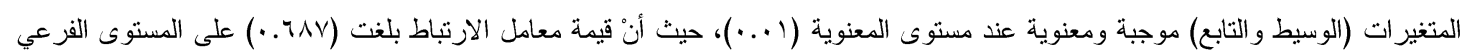

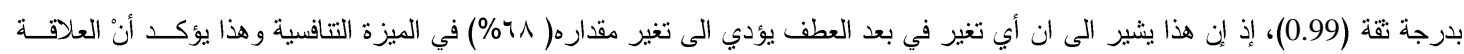

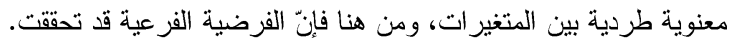


Correlations قدول رقم (V) قيمة معامل الارتباط بين بعد العطف والميزة التنافسية

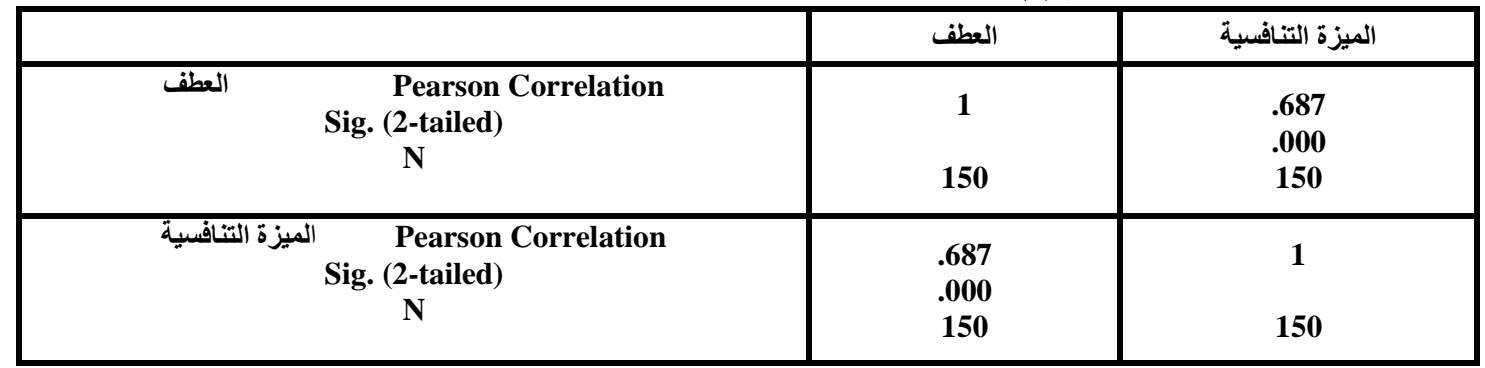

**. Correlation is significant at the 0.01 level (2-tailed).

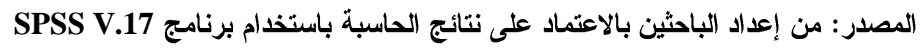

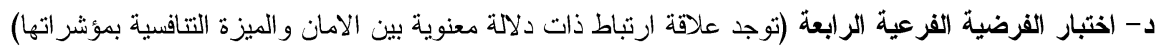

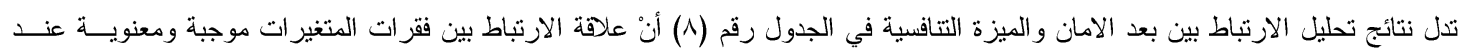

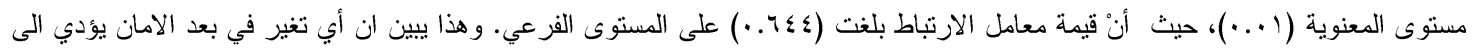
تغير مقداره( ء؟\%) في الميزة التتافية وهذا يؤكد أنْ العلاقة معنوية طردية بين المتغيرات، ومن هنا فإنّ الفرضية الفرعية قد تحققت.

جدول رقم (^) قيمة معامل الارتباط بين بعد الامان والميزة التنافسية Correlations

\begin{tabular}{|c|c|c|c|}
\hline & & الامان & الميزة التنافسية \\
\hline \multirow[t]{3}{*}{ الامان } & Pearson Correlation & 1 & .644 \\
\hline & Sig. (2-tailed) & & .000 \\
\hline & $\mathbf{N}$ & 150 & 150 \\
\hline \multirow{3}{*}{ التنافسيةة } & Pearson Correlation & .644 & 1 \\
\hline & Sig. (2-tailed) & .000 & \\
\hline & $\mathbf{N}$ & 150 & 150 \\
\hline
\end{tabular}

SPSS V.17 المصدر : من إعداد الباحثين بالاعنماد على نتائج الحاسبة باستخذام برنامج

\section{أ- اختبار الفرضية الفرعية الخامسة}

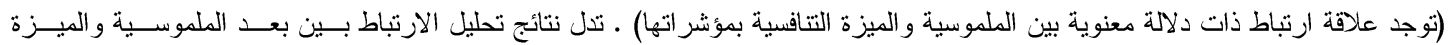

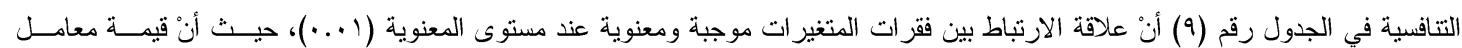

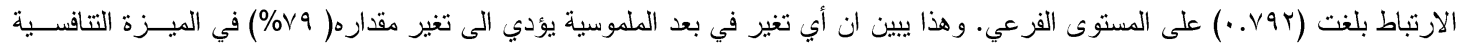

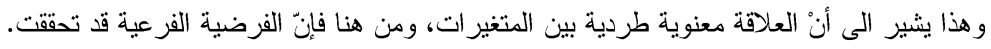

جدول رقم (9) قيمة معامل الارتباط بين بعد الملموسية والميزة التنافسية Correlations

\begin{tabular}{|c|c|c|c|}
\hline & & الملموسية & الميزة التنافسية \\
\hline الملموسية & $\begin{array}{l}\text { Pearson Correlation } \\
\text { Sig. (2-tailed) } \\
\text { N }\end{array}$ & $\begin{array}{c}1 \\
150\end{array}$ & $\begin{array}{l}.792 \\
.000 \\
150\end{array}$ \\
\hline الميزة التنافسية & $\begin{array}{c}\text { Pearson Correlation } \\
\text { Sig. (2-tailed) } \\
\text { N }\end{array}$ & $\begin{array}{l}.792 \\
.000 \\
150\end{array}$ & $\begin{array}{c}1 \\
150\end{array}$ \\
\hline
\end{tabular}

SPSS V.17 المصدر : من إعداد الباحثين بالاعتماد على نتائج الحاسبة باستخدام برنامج 


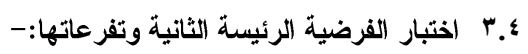

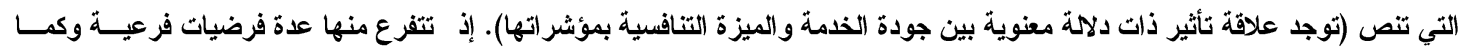
موضح في ادناه:أ- علاقة التأثثر بين الاعتمادية والميزة التنافسية

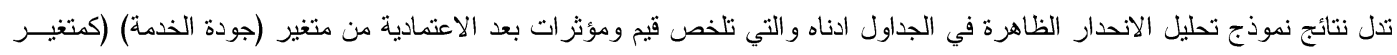

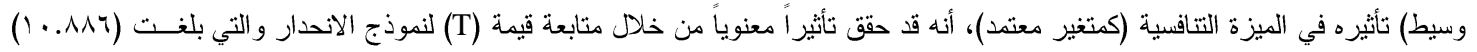
وهي اكبر من القيمة المجدولة

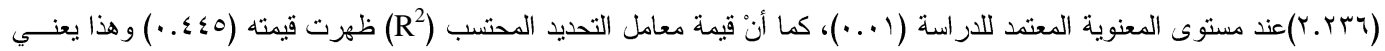

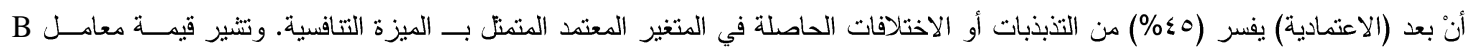

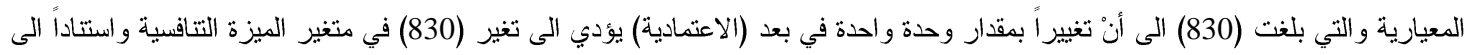

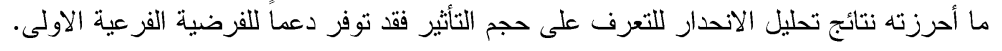

Model Summary جدول رقم (• (1)ملخص الانموذج

\begin{tabular}{|c|c|c|c|c|c|}
\hline Model & $\mathrm{R}$ & $\mathrm{R}$ Square & Adjusted R Square & Std. Error of the Estimate & N \\
\hline 1 & .667 & .445 & .441 & .54410 & 150 \\
\hline
\end{tabular}

Spss v. 17 المصدر : من اعداد الباحثين بالاعتماد على نتائج الحاسبة باستخدام برنامج

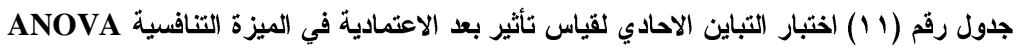

\begin{tabular}{|c|c|c|c|c|c|}
\hline Model & Sum of Squares & Df & $\begin{array}{c}\text { Mean } \\
\text { Square }\end{array}$ & F & Sig. \\
\hline Regression & 35.080 & 1 & 35.080 & 118.497 & .00 \\
Residual & 43.814 & 148 & .296 & & \\
Total & 78.894 & 149 & & & \\
\hline
\end{tabular}

SPSS V.17 المصدر : من إعداد الباحثين بالاعتماد على نتائج الحاسبة باستخدام برنامج جدول رقم (ץ ا) اختبار معنوية انموذج تحليل الاحدار البسيط لقياس تأثير بعد الاعتمادية في متغير الميزة التنافسية Coefficients $^{\text {a }}$

\begin{tabular}{|l|c|c|c|l|l|}
\hline \multirow{2}{*}{ Model } & \multicolumn{2}{|c|}{ Un standardized Coefficients } & $\begin{array}{c}\text { Stand } \\
\text { Coefficients }\end{array}$ & \multirow{2}{*}{ T } & Sig. \\
\cline { 2 - 5 } & B & Std. Error & Beta & 1.726 & .087 \\
Constant & .513 & .297 & & .687 & .000 \\
\hline
\end{tabular}

SPSS V.17 المصدر : من إعداد الباحثين بالاعتماد على نتائج الحاسبة باستخدام برنامج

ب- علاقة التأثير بين الاستجابة والميزة التنافسية

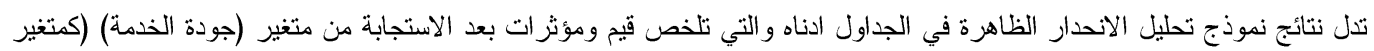

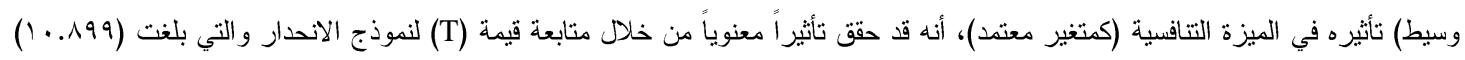

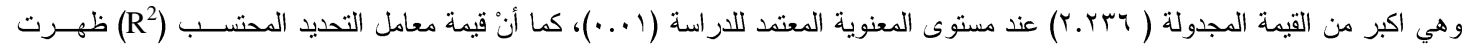

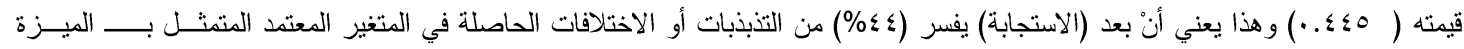


التتافسية. ونتئير قيمة معامل B المعيارية و التي بلغت (758. ) الى أنْ تغييراً بمقدار وحدة واحدة في بعد (الاستجابة) يؤدي الى تغيـر (758. )

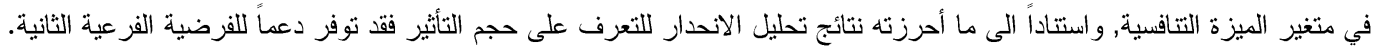

Model Summary جدول رقم (r ا ) ملخص الانموذج

\begin{tabular}{|c|c|c|c|c|c|}
\hline Model & R & R Square & Adjusted R Square & $\begin{array}{c}\text { Std. Error of the } \\
\text { Estimate }\end{array}$ & N \\
\hline 1 & .667 & .445 & .442 & .54380 & 150 \\
\hline
\end{tabular}

SPSS V.17 المصدر : من إعداد الباحثين بالاعتماد على نتائج الحاسبة باستخدام برنامج

\begin{tabular}{|c|c|c|c|c|c|}
\hline Model & Sumof Squares & Df & Mean Square & F & Sig. \\
\hline Regression & 35.128 & 1 & 35.128 & 118.791 & .000 \\
Residual & 43.766 & 148 & .296 & & \\
Total & 78.894 & 149 & & & \\
\hline
\end{tabular}

SPSS V.17 المصدر : من إعداد الباحثين بالاعتماد على نتائج الحاسبة باستخذام برنامج

Coefficients جدول رقم (ه 1) اختبار معنوية انموذج تحليل الاحدار البسيط لقياس تأثير بعد الاستجابة في الميزة التنافسية

\begin{tabular}{|c|c|c|c|c|c|}
\hline \multirow{2}{*}{ Model } & \multicolumn{2}{|c|}{ Un-standardized Coefficients } & $\begin{array}{c}\text { Stand } \\
\text { Coefficients }\end{array}$ & \multirow{2}{*}{$\mathbf{T}$} & \multirow{2}{*}{ Sig. } \\
\hline & B & Std. Error & Beta & & \\
\hline Constant & .769 & .273 & & 2.813 & .006 \\
\hline الاستجابة & .758 & .070 & .667 & 10.899 & .000 \\
\hline
\end{tabular}

SPSS V.17 المصدر : من إعداد الباحثين بالاعتماد على نتائج الحاسبة باستخدام برنامج

ج- علاقة التأثير بين العطف والميزة التنافسية

تندل نتائج نموذج تحليل الانحدار الظاهرة في الجداول ادناه والتي تلخص قيل ولئ ومؤثرات بعد العطف من متغير (جودة الخدمة) (كمتغير وسيط)

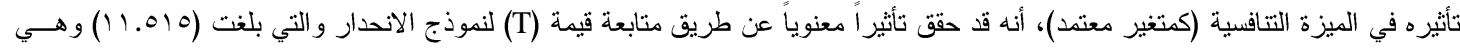

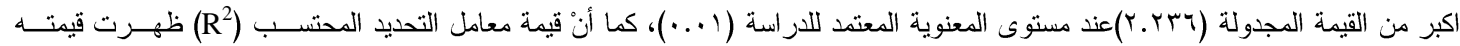

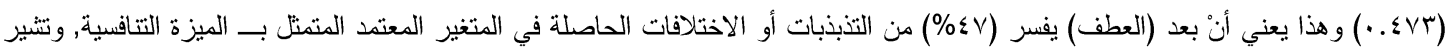

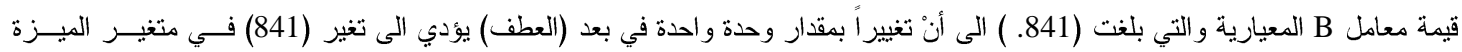
التتافسية واستتاداً الى ما أحرزته نتائج تحليل الانحدار للتعرف على حلى حم التأثير فقد توفز دعماً للفرضية الفرعية الثالثة.

Model Summary جدول رقم (17 ) ملخص الانموذج

\begin{tabular}{|c|c|l|c|lc|c|}
\hline Model & $\mathrm{R}$ & R Square & Adjusted R Square & Std. Error of the & $\mathrm{N}$ \\
\hline 1 & .687 & .473 & .469 & $\mathbf{5 3 0 2 4}$ & 150 \\
\hline
\end{tabular}

SPSS V.17 المصدر : من إعداد الباحثين بالاعتماد على نتائج الحاسبة باستخدام برنامج 
جدول رقم (IV) اختبار التباين الاحادي لقياس تأثير بعد العطف في الميزة التنافسية ANOVA

\begin{tabular}{|c|c|c|c|c|c|}
\hline Model & Sum of Squares & Df & Mean Square & F & Sig. \\
\hline Regression & 37.283 & 1 & 37.283 & 132.606 & .000 \\
Residual & 41.611 & 148 & .281 & & \\
Total & 78.894 & 149 & & & \\
\hline
\end{tabular}

SPSS V.17 المصدر : من إعداد الباحثين بالاعتماد على نتائج الحاسبة باستخدام برنامج

جلول رقم (^ ا ) اختبار معنوية انموذج تحليل الانحدار البسيط لقياس تأثير بعد العطف في متغير الميزة التنافسية Coefficients

\begin{tabular}{|c|c|c|c|c|c|}
\hline \multirow{2}{*}{ Model } & \multicolumn{2}{|c|}{ Unstandardized Coefficients } & $\begin{array}{l}\text { Stand } \\
\text { Coefficients }\end{array}$ & \multirow{2}{*}{$\mathbf{T}$} & \multirow{2}{*}{ Sig. } \\
\hline & B & Std. Error & Beta & & \\
\hline $\begin{array}{c}\text { Constant } \\
\text { العطف }\end{array}$ & $\begin{array}{l}.325 \\
.841\end{array}$ & $\begin{array}{l}.297 \\
.073\end{array}$ & .687 & $\begin{array}{c}1.095 \\
11.515\end{array}$ & $\begin{array}{l}.275 \\
.000\end{array}$ \\
\hline
\end{tabular}

SPSS V.17 المصدر: من إعداد الباحثين بالاعتماد على نتائج الحاسبة باستخدام برنامج

د- علاقة التأثير بين الامان والميزة التنافسية

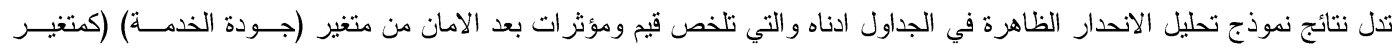

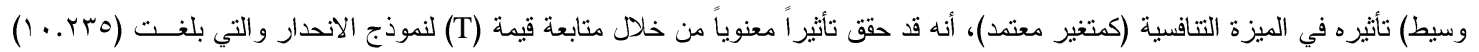

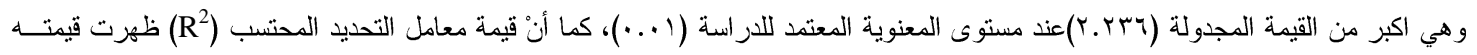

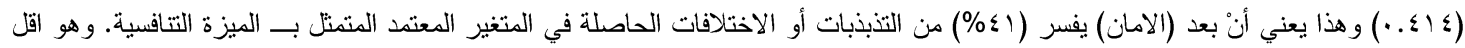

نسبيا من متغير العطف.

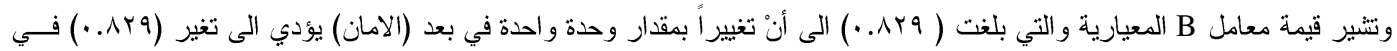

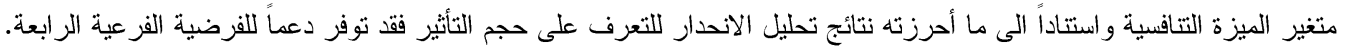

Model Summary جدول رقم (9 1 ) ملخص الانموذج

\begin{tabular}{|c|c|c|c|c|l|}
\hline Model & R & R Square & Adjusted R Square & $\begin{array}{c}\text { Std. Error of the } \\
\text { Estimate }\end{array}$ & N \\
\hline 1 & .644 & .414 & .410 & .55869 & 150 \\
\hline
\end{tabular}

SPSS V.17 المصدر : من إعداد الباحثين بالاعتماد على نتائج الحاسبة باستخدام برنامجل

جدول رقم (·r) اختبار التباين الاحادي لقياس تأثير بعد الامان في الميزة التنافسيةANOVA

\begin{tabular}{|c|c|c|c|c|c|}
\hline Model & Sum of Squares & Df & Mean Square & F & Sig. \\
\hline Regression & 32.698 & 1 & 32.698 & 104.755 & .000 \\
Residual & 46.196 & 148 & .312 & & \\
Total & 78.894 & 149 & & & \\
\hline
\end{tabular}

SPSS V.17 المصدر : من إعداد الباحثين بالاعتماد على نتائج الحاسبة باستخذام برنامج 
جدول رقم (اب) اختبار معنوية انموذج تحليل الاحدار البسيط لقياس تأثير بعد الامان في متغير الميزة التنافسيةCoefficients

\begin{tabular}{|c|c|c|c|c|c|}
\hline \multirow{2}{*}{ Model } & \multicolumn{2}{|c|}{ Un standardized Coefficients } & \multirow{2}{*}{$\begin{array}{c}\begin{array}{c}\text { Stand } \\
\text { Coefficients }\end{array} \\
\text { Beta }\end{array}$} & \multirow{2}{*}{$\mathbf{T}$} & \multirow{2}{*}{ Sig. } \\
\hline & $\mathbf{B}$ & Std. Error & & & \\
\hline Constant & .399 & .327 & & 1.220 & .224 \\
\hline 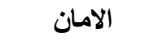 & .829 & .081 & .644 & 10.235 & .000 \\
\hline
\end{tabular}

SPSS V.17 المصدر : من إعداد الباحثين بالاعتماد على نتائج الحاسبة باستخدام برنامج

ح- علاقة التأثير بين الملموسية والميزة التنافسية

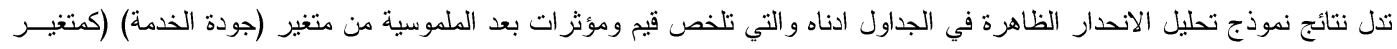

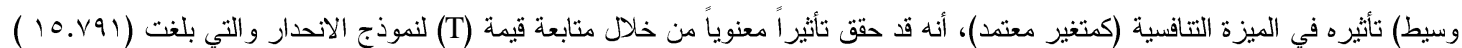

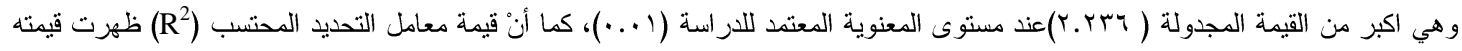

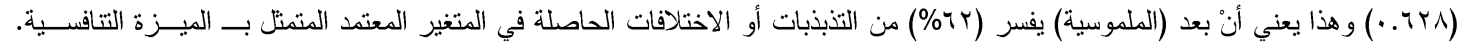

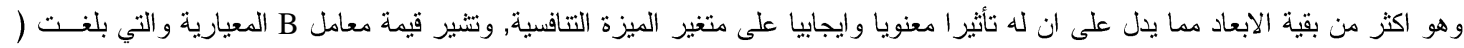

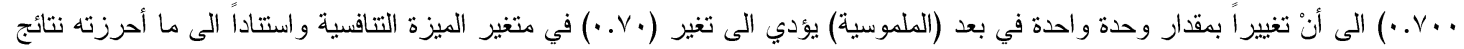

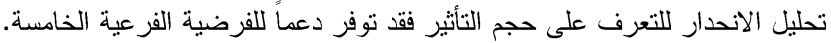

Model Summary جدول رقم (Y M) ملغص الانموذج

\begin{tabular}{|c|c|c|c|c|c|}
\hline Model & R & R Square & Adjusted R Square & $\begin{array}{c}\text { Std. Error of the } \\
\text { Estimate }\end{array}$ & N \\
\hline 1 & .792 & .628 & .625 & .44559 & 150 \\
\hline
\end{tabular}

SPSS V.17 المصدر : من إعداد الباحثين بالاعتماد على نتائج الحاسبة باستخدام برنامج

ANOVA جدول رقم (r r) اختبار التباين الاحادي لقياس تأثير بعد الملموسية في الميزة التنافسبة)

\begin{tabular}{|c|c|c|c|c|c|}
\hline Model & Sum of Squares & Df & Mean Square & F & Sig. \\
\hline Regression & 49.508 & 1 & 49.508 & $\mathbf{2 4 9 . 3 4 6}$ & .000 \\
Residual & 29.386 & 148 & 199 & & \\
Total & 78.894 & 149 & & & \\
\hline
\end{tabular}

SPSS V.17 المصدر : من إعداد الباحثين بالاعتماد على نتائج الحاسبة باستخدام برنامج

جدول رقم (؟) اختبار معنوية انموذج تحليل الاحدار البسيط لقياس تأثير بعد الملموسية في متغير الميزة التنافسية Coefficients

\begin{tabular}{|c|c|c|c|c|c|}
\hline \multirow{2}{*}{ Model } & \multicolumn{2}{|c|}{ Un-standardized Coefficients } & \multirow{2}{*}{$\begin{array}{c}\text { Stand Coefficients } \\
\text { Beta }\end{array}$} & \multirow{2}{*}{$\mathbf{T}$} & \multirow{2}{*}{ Sig. } \\
\hline & B & Std. Error & & & \\
\hline Constant & I.rr. & .156 & .792 & 8.479 & .000 \\
\hline الملموسية & .700 & .044 & & 15.791 & .000 \\
\hline
\end{tabular}

SPSS V.17 المصدر : من إعداد الباحثين بالاعتماد على نتائج الحاسبة باستخدام برنامج 
ه. با: المحاكاة: هي الامتداد الطبيعي و المنطقي للطرق التحليلية في جميع العلوم اذ يعد أسلوب المحاكاة لغة العصر لأنه يسـاعد البـاحثين فـي البـي

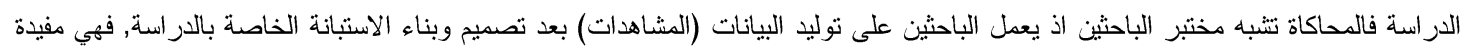

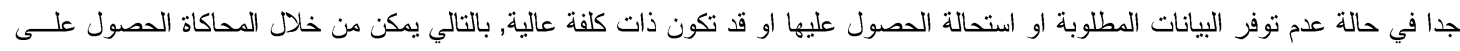

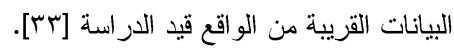

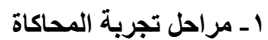

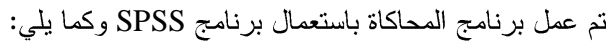

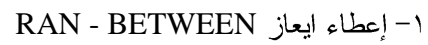

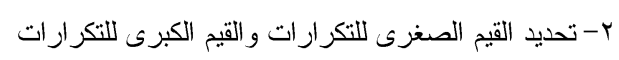

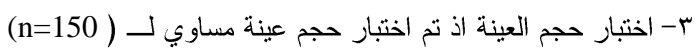

ع-مرحلة توليد البيانات وهي من المراحل المهمة التي تعتمد عليها حساب المقاييس المهمة, وفي هذه المرحلة يتم توليد البيانات (المشاهدات) لجميع فقرات الاستبانة التي تم تصميمها مسبقا وفقا لمقياس ليكرد الخماسي لعينة حجمها (n=150).

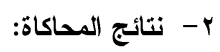

من استخدام المحاكاة تم توليد البيانات (المشاهدات) على فقرات استمارة الاستبانة حجمها (n=150) ومن خلالها تم حساب الوسط الحسـابي لكل فقرة من فقر ات استمارة الاستبانة الرئيسية و الفرعية.

\begin{tabular}{|c|c|c|c|c|c|c|c|c|c|c|c|}
\hline \multicolumn{6}{|c|}{ جودة الخدمة } & \multicolumn{5}{|c|}{ الميزة التنافسية } & \multirow[b]{2}{*}{ ON } \\
\hline M1 & M2 & M3 & M4 & M5 & $\mathbf{M}$ & Y1 & Y2 & Y3 & Y4 & $\mathbf{Y}$ & \\
\hline 3.85 & 3.87 & 4.02 & 3.99 & 3.41 & 3.82 & 3.61 & 3.64 & 3.76 & 3.75 & 3.69 & المعدل \\
\hline
\end{tabular}

ملاحظة: يرمز للمتغير المستقل (جودة الخدمة) بالرمز (M)، يرمز للمتغير المعتمد (الميزة التتافسية) بالرمز (Y)

الجدول رقم (Y0) الوسط الحسابي للعينة المولدة

المصدر: من إعداد الباحثين بالاعتماد على نتائج الحاسبة باستخدام برنامج اكسل

$$
\text { يتضح لنا من النتائج المذكورة في الجدول رقم (Y0) ما يأتي:- }
$$

بلغ الوسط الحسابي لمتغير جودة الخدمة (M) الكلي ما يقارب (Y^.^r) وهو اكبر من الوسط الفرضي البالغ (3) وهذا يدل على ان المنظمة تولي اهنماما لا بأس به للجودة في خدماتها.

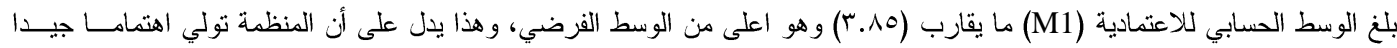

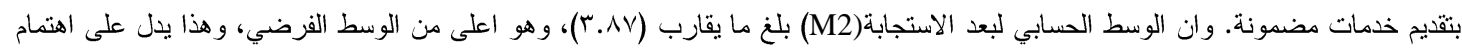

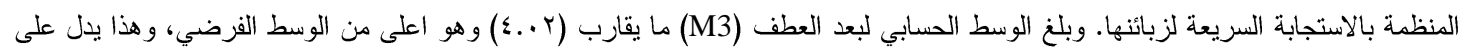

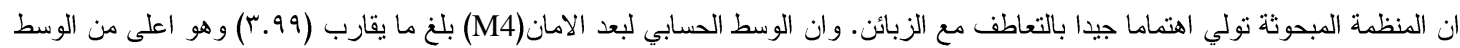

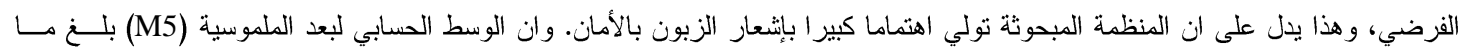
يقارب (اء.؟r) وهو اعلى من الوسط الفرضي، وهذا يدل على ان المنظمة المبحوثة تولي الهتماما الى حد ما بالمظهر.

بلغ الوسط الحسابي لمتغير الميزة التتافسية (Y) الكلي ما يقارب (79.ب) وهو اكبر من الوسط الفرضي البالغ (3) وهذا يـدل علـى ان المنظمة تتمتع بدرجة جيدة من المنافسة بين المنظمات الاخرى.

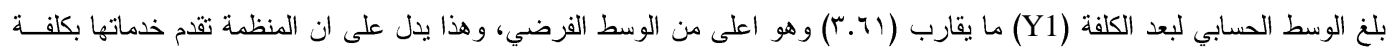

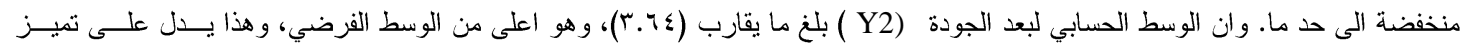

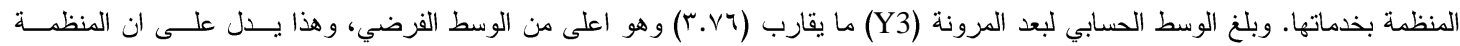

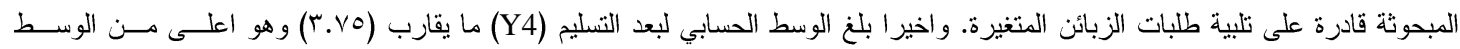

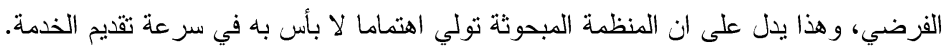


في هذا المبحث سنتاول فقرتين, تعنى الاولى منهما بعرض اهم ما توصلت اليه الدراسة من استتناجات, واما الثاني فيتضمن ابرز التوصيات والمقترحات التي يروم الباحثين التأكيد عليها.

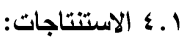

سنستعرض في هذه الفقرة اهم الاستتناجات التي توصلت اليها الدراسة استتاداً الى الجانب النظري وما افرزته نتائج التحليل الاحصائي التي تم مناقتنها في الجانب الميداني من الدر اسة:

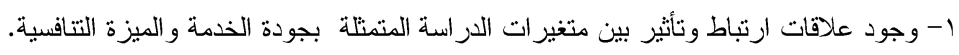

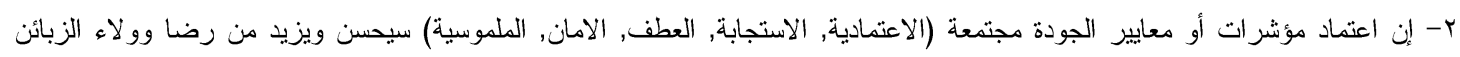
وبالتالي يحقق قدرة وتفوق المنظمة على منافسيها. ب- بعد تحليل استجابات عيّنة الدر اسة وفقا لبعد الاعتمادية, تبين اهتمام المنظمة بشكل ملحوظ بتوفير انظمة التوثيق و السجلات الدقيقة لما لها من

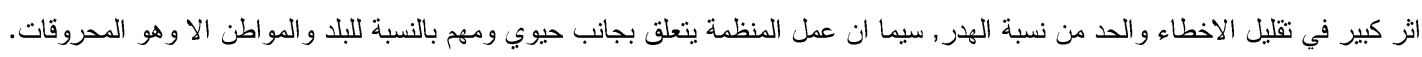

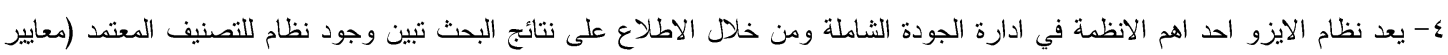

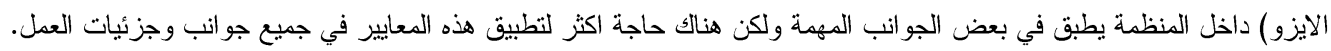

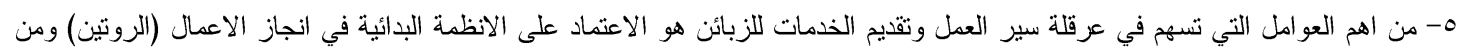

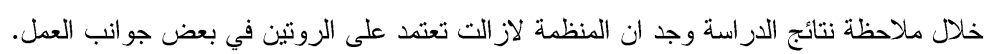

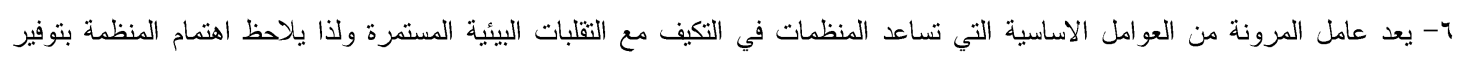

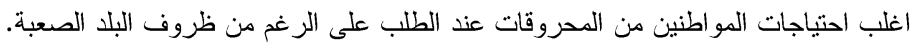
V- بعد الزيارات المتكررة للمنظمة محل البحث وبعد الاطلاع على خطة سير العمل ومن خلال النتائج التي تم التوصل اليها في التي الجانب التطبيقي

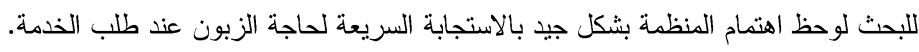

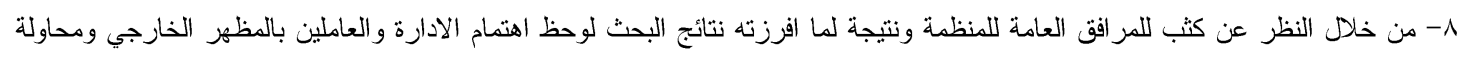
ابراز الجانب الجمالي فيها.

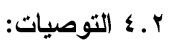

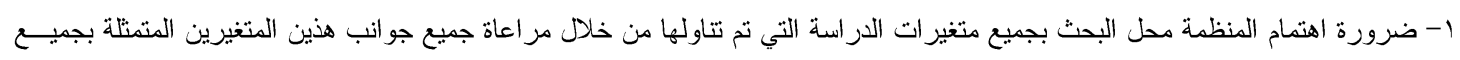

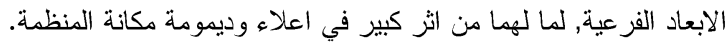

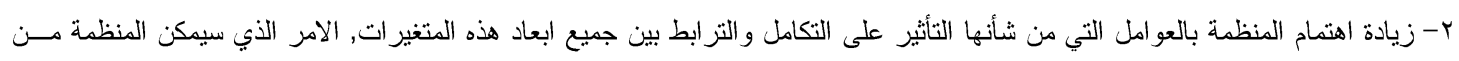
تجاوز العقبات وتحقيق النتائج المرجوة. ب- الاهتمام بالحفاظ على ابعاد الجودة (الاعتمادية, الاستجابة, العطف, الامان, الملموسية ) و الالتز ام بها لأنها الأساس في تحقيق رضـا الزبـائن وزيادة و لائهم اللمنظمة. ع- من الافضل للمنظمة الاهتمام بشكل جدي بمعايير الجودة (معايير الايزو) و السعي الحثيث لإدخال هذه المعايير في جميـع مفاصـل العمـل

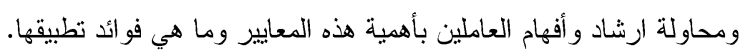
ه- من الامور التي تحسب لصالح المنظمة محل البحث اهتمامها بسر عة الاستجابة لطلبات الزبائن لذا فمن المهر بالنسبة للمنظمة الحفاظ على هذه المكتسبات وتتميتها. צ- ان تطوير اساليب العمل ومحاولة ادخال التقنيات والتكنولوجيا الحديثة يعد من الامور المهمة التي لا غنى عنها بالنسبة للمنظمات المعاصرة

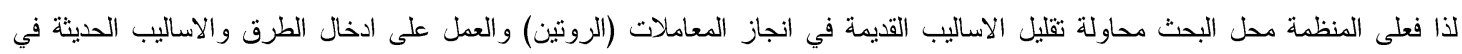




\section{CONFLICT OF INTERESTS}

\section{There are no conflicts of interest.}

[1] Thapa, Santosh, "Derendency of Serves Quality on Human Resources Development, A survey conducted for cleaning company", Master Thesis, University of Applied Sciences, 2017.

[2] Zikmund and al., "Business research methods", 8th ed. South-Western Cengage Learning, Canada. p. 199, 2010

[3]Businessdictionary.2017.Available:http://www.businessdictionary.com/defnition/servicequal-ity.html. Accessed $\underline{19 \text { July } 2017 .}$

[4] Lovelock, C., Wirtz, Jochen, Lapert, D., \& Munos, "A. Marketing des services", 6 ed. Paris, Pearson Education, 2008.

[5] Hoffman, K. Douglas, Bateson, John. E.G, "Services Marketing, Concepts, Strategies",\& Cases, SouthWestern, Cengage Learning, U.S.A, 2011.

$$
\begin{aligned}
& \text { [־] الدراركة, مأمون سليمان, "ادارة الجودة الثاملة وخدمة العملاء", دار صفاء للنشر و التوزيع, عمان, الاردن, ؟ .. ؟. } \\
& \text { [V] اسلام, قر اوي, محمد, غازي, "تأثير جودة الخدمة على رضا الزبون الخارجي", ( دراسة حالة الفرع التجاري لمؤسسة نفط الوحدة البويرة), }
\end{aligned}
$$

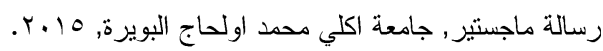

[8] Heizer, Joy, Render, Barry, "Operation Management", 10² edition, Prentice-Hall, Jersey, 2011.

$$
\begin{aligned}
& \text { [9] عبد النبي, نور صلاح, "قياس تأثير ابعاد جودة الخدمة والرضا الوظيفي على التعامل مع زبائن المصرف" ,(بحث تطبيقي دبلوم عالي فـي المي }
\end{aligned}
$$

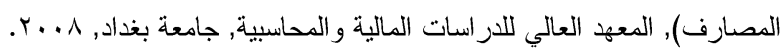

$$
\begin{aligned}
& \text { [• • [ حسين, انتصار عزيز، "اثر التحليل الاستر اتيجي في جودة الخدمة", رسالة ماجستير , الجامعة المستتصــرية, كليــة الادارة والاقتصــاد, } \\
& \text {.r. . . } \\
& \text { [1 إ] علوان, قاسم نايف, "ادارة الجودة في الخدمات مفاهيم وعمليات وتطبيقات", دار الشروق للنشر و التوزيع, القــاهرة, جمهوريــة مصــر } \\
& \text { العربية, طا, ؟ ...r. }
\end{aligned}
$$

[12] Evans, James R ., \& Collier, David A., "Operations Management", $2^{\text {rd }}$ ed Thomson South We/stern, Boston, 2007.

[13] An, M., Noh, Y., "Airline customers' satisfaction and loyalty: impact of inflight service quality". Serv. Bus. $3(3), 2009$

[14] Siddiqi, K. "Interrelations between service quality attributes, customer satisfaction, and customer loyalty in the retail banking sector in Bangladesh". International Journal of Business and Management, 6(3), 2011.

[15] Keisidou, E., Sarigiannidis, L., Maditinos, D. I., \& Thalassinos, E. I. "Customer satisfaction, loyalty, and financial performance". International Journal of Bank Marketing, 31, 2013

[16] Dehghan, A., Zenouzi, B., \& Albadvi, A." An investigation on the relationship between service quality and customer satisfaction: In the case of CCG Co." International Business Research, 5, 2012.

[17] Lundstrom, W.J., Dixit, A., Is trust "Trustworthy in customers' relationship management?" J. Acad. Bus. Econ.8(2), 2008.

[18] Evans, James, et al, "Operation Management(OM)", South Western, Cengage Learning, USA.2013.

[19] Kotler, P. and Keller, K. L. "Marketing Management". 14th e patah et al dition, New Jersey: Pearson Prentice Hall, 2012.

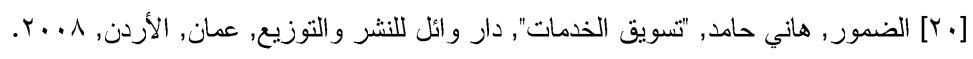




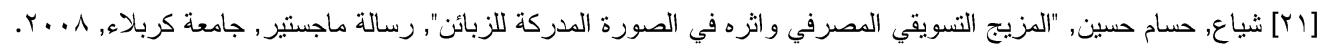

$$
\begin{aligned}
& \text { [بr] السالم، مؤيد، "إدارة الموارد البشرية ، النهج الاستر اتيجي المتكامل" ، الطبعة الأولى، دار نشر أنغيرا، عمان، الأردن ، 9. . ؟. }
\end{aligned}
$$

[23]Wang, Wen Cheng, Lin, Chien Hung \& Chu, Ying Chien, "Types of Competitive Advantage and Analysis", International Journal of Business and Management, Vol.(6), No.(5), pp:(100-104), 2011.

[24] Progress, Hove ; Whilhemia, Smith \& Tarisai, Chikungwa, "The Delineation of Porter's Five Competitive Forces Model from a Techno-logical Marketing Perspective : A Case Study of Buffalo City Metropolitan Municipality", International Journal of Economics and Management Studies, Vol.(4), No.(2), pp:(169-182), 2013.

[25] Lynch, John \& Ariely, Dean, "Search Costs Affect Competition on Price, Quality and Distribution", Journal of Marketing Science, Vol.(19), No.(1), pp:(83-103), 2000.

[26] Baidoum, Samir, "An Empirical Study of Critical Factors of TQM in Palestian Organizations", Journal of Logistic Information Management, Vol.(16), No.(2), pp:(156-171), 2003.

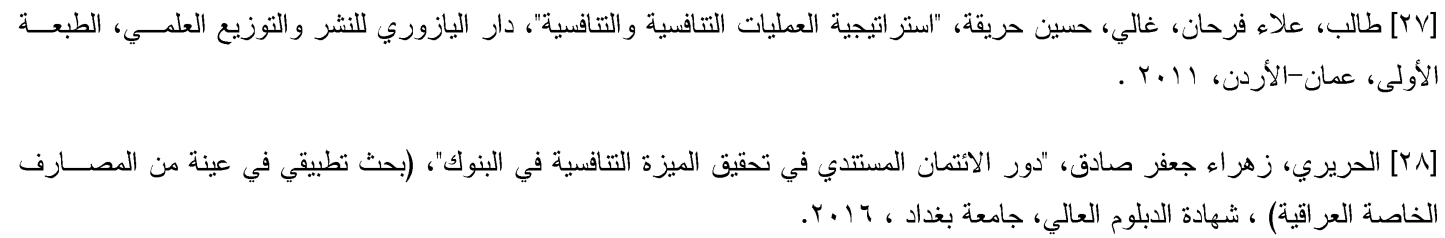

[29] Krajewski, L. J.; Ritzman, L.P. \& Malhotra, M. K, "Operations Management: Process \& Supply Chains", 9th ed, Pearson, New York, 2010.

[30] Slack, Nigel, Chambers, Stuat \& Johnston, Robert, "Operation management" 6ed Prentice Hall, New Jersey, 2010.

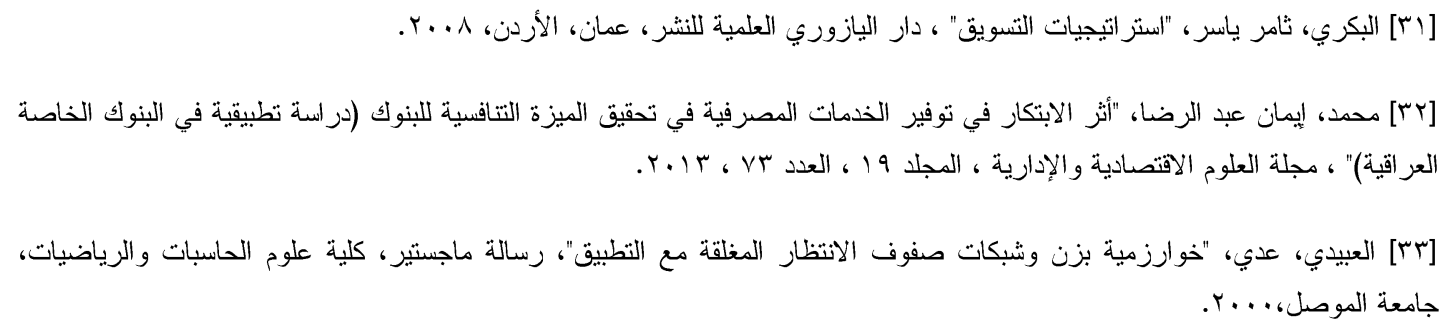

